UNIVERSIDADE DE SÃO PAULO

FACULDADE DE ECONOMIA, ADMINISTRAÇÃO E CONTABILIDADE DEPARTAMENTO DE ECONOMIA PROGRAMA DE PÓS-GRADUAÇÃO EM ECONOMIA

Esforço Fiscal e a Compensação Financeira pela Utilização dos Recursos Hídricos nos Municípios Brasileiros

Alexander Brian Chow

Orientador: Prof. Dr. Fernando Antonio Slaibe Postali

SÃO PAULO

2016 



\title{
Esforço Fiscal e a Compensação Financeira pela Utilização dos Recursos Hídricos nos Municípios Brasileiros
}

\author{
Dissertação de Mestrado apresentada ao \\ Programa de Mestrado em Teoria \\ Econômica do Departamento de Economia \\ da Universidade de São Paulo, como \\ requisito para a obtenção do título de Mestre \\ em Teoria Econômica. \\ Área de concentração: Microeconomia \\ Aplicada \\ Orientador: \\ Prof. Dr. Fernando Antonio Slaibe Postali
}

\section{VERSÃO CORRIGIDA}

(versão final disponível na Faculdade de Economia, Administração e Contabilidade)

\section{SÃO PAULO}


FICHA CATALOGRÁFICA

Elaborada pela Seção de Processamento Técnico do SBD/FEA/USP

Chow, Alexander Brian

Esforço fiscal e a compensação financeira pela utilização dos recursos hídricos nos municípios brasileiros / Alexander Brian Chow. -São Paulo, 2016.

$57 \mathrm{p}$.

Dissertação (Mestrado) - Universidade de São Paulo, 2016.

Orientador: Fernando Antonio Slaibe Postali.

1. Finanças públicas 2. Economia fiscal 3. Econometria 4. Economia de energia I. Universidade de São Paulo. Faculdade de Economia, Administração e Contabilidade. II. Título.

$$
\text { CDD - } 336
$$




\section{AGRADECIMENTOS}

Inicialmente, gostaria de agradecer o apoio financeiro prestado pela Fundação de Amparo à Pesquisa do Estado de São Paulo (FAPESP), por meio do processo n 2014/19241-0.

Agradeço também à Universidade de São Paulo, em especial à Faculdade de Economia, Administração e Contabilidade (FEA-USP) e ao Instituto de Pesquisas Econômicas (IPEUSP) pela sólida formação que me foi proporcionada desde a graduação.

Ao meu orientador, Professor Dr. Fernando Antonio Slaibe Postali, não só por toda a ajuda prestada, como também pelo seu comprometimento e disponibilidade exemplares. Agradeço também à Professora Dra. Maria Dolores Montoya Diaz e à Professora Dra. Fabiana Fontes Rocha, pelas contribuições fundamentais para o desenvolvimento do tema do melhor modo possível.

À todos os meus colegas de mestrado, pelas conversas, risadas, trabalhos, dicas, conselhos e, principalmente, amizades que levarei para sempre comigo.

Agradeço à Professora Dra. Vera Lúcia Fava, Professora Dra. Maria Dolores Montoya Diaz, Professor Dr. Rodrigo de Losso da Silveira Bueno e ao Professor Dr. Danilo Camargo Igliori pelas oportunidades de ser monitor de suas disciplinas, uma experiência incrível e de muita aprendizagem. Aos meus alunos de monitoria, pelo respeito com que me trataram.

Ao Tiago pela ajuda com o mapa.

Por fim, agradeço à minha família, pelo apoio incondicional à todas as minhas decisões, e por estarem comigo sempre que precisei. Agradeço à minha mãe, Linde, por ser essa pessoa maravilhosa e alegre, ao meu pai, Chow, pelo respeito e pelas conversas sobre economia e ao meu irmão, Christopher, pelas críticas construtivas e por ter me suportado todos os dias. Aos meus amigos, Luan, Guill, João, Rafael, Guilherme, Leonardo, Tati, Bia, Isa e James pela sinceridade e apoio total. E à Dayana, pela fé e pelo amor que deposita em mim. Nunca teria conseguido sem vocês todos. 



\section{Resumo}

Esta dissertação de mestrado em teoria econômica tem como objetivo verificar se a Compensação Financeira pela Utilização de Recursos Hídricos (CFURH) paga a municípios que abrigam usinas hidrelétricas ou reservatórios impacta seu esforço arrecadatório. A importância dessa análise vem do fato de que um possível relaxamento fiscal por parte deles pode por em risco o seu desenvolvimento, dado que a compensação pode sofrer variações no tempo, e dado que sua duração depende da vida útil das usinas. Será utilizada a metodologia de fronteira estocástica, com base em um painel de dados relativo aos municípios brasileiros entre 2007 e 2012 Os resultados mostram que, em geral, os municípios beneficiários são menos eficientes na arrecadação de tributos do que os não beneficiários.

Palavras-chave: Esforço fiscal, análise de fronteira estocástica, compensação financeira pela utilização dos recursos hídricos 



\begin{abstract}
This Master's dissertation in Economic Theory aims to verify whether the water windfalls paid to municipalities that hold hydroelectric power stations or water reservoirs have any impact on their fiscal effort. The issue is relevant since a reduced tax effort may pose a threat to the municipalities' development, since these resources can vary in time and since it may have an end due to the power plant's useful life. It will be used the stochastic frontier technique applied to a panel data of Brazilian municipalities between 2007 and 2012. The results show that, in a general way, the municipalities that benefit from the water windfalls are more inefficient than those which don't receive these resources.
\end{abstract}

Keywords: Fiscal effort, stochastic frontier analysis, water resource windfalls 



\section{Sumário}

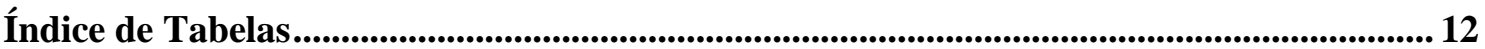

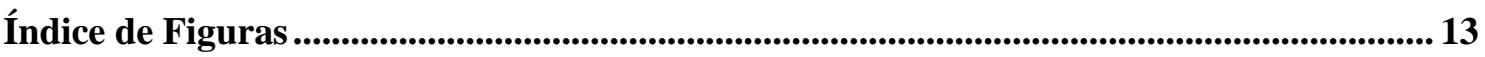

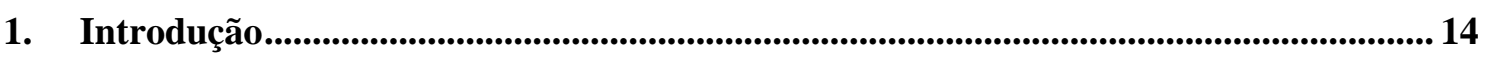

1.1. Recursos Hídricos e a CFURH no Brasil ...................................................................... 17

1.2. Esforço Fiscal no Brasil ............................................................................................ 19

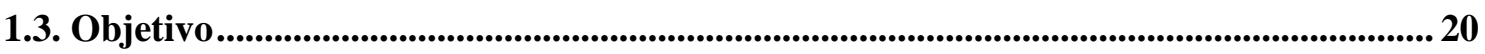

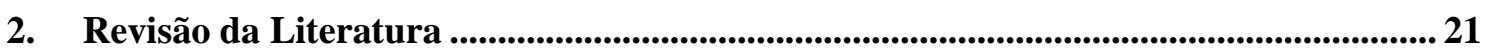

2.1. Recursos Naturais e Compensações Financeiras.................................................................. 21

2.2. Transferências Verticais e Esforço Fiscal ........................................................................................ 22

2.3. Fronteira Estocástica ............................................................................................................ 24

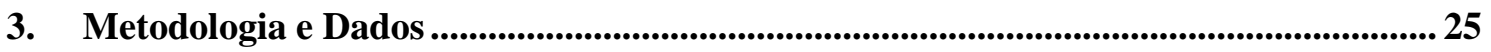

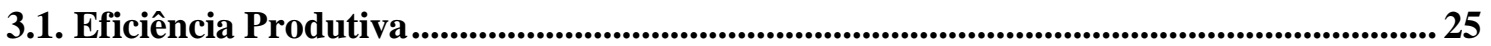

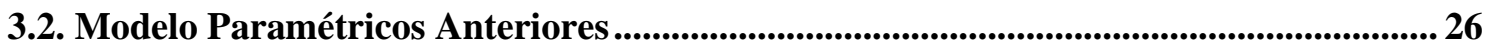

3.3. Modelo de Fronteira Estocástica - Cross-Section ................................................................. 27

3.4. Modelo de Fronteira Estocástica - Painel.......................................................................... 28

3.5. Discussões Sobre a Metodologia de Fronteiras Estocásticas .............................................. 29

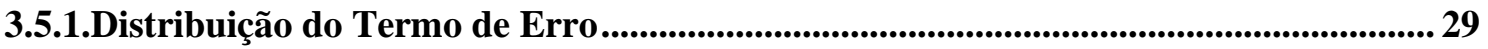

3.5.2.Forma Funcional da Função de Produção............................................................................... 30

3.6. Metodologias Alternativas para Análise de Eficiência......................................................... 32

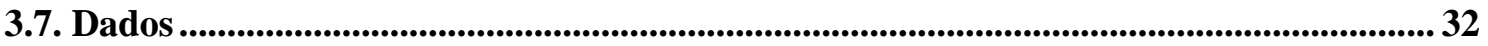

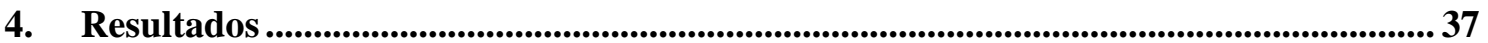

4.1. Especificação dos Modelos.................................................................................................................. 37

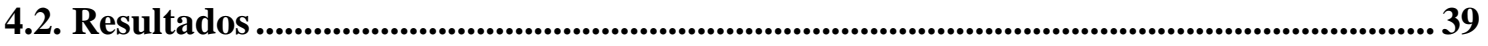

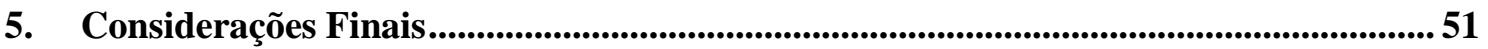

6. Referências............................................................................................................................................. 53 


\section{Índice de Tabelas}

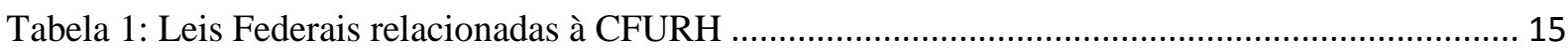

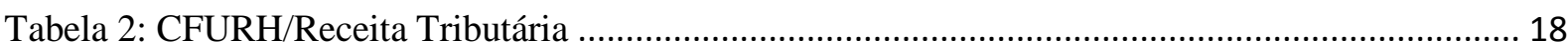

Tabela 3: Estatísticas Descritivas - Base Completa (empilhado) ........................................................ 35

Tabela 4: Estatísticas Descritivas - Bace Centro-Sul (empilhado)......................................................... 36

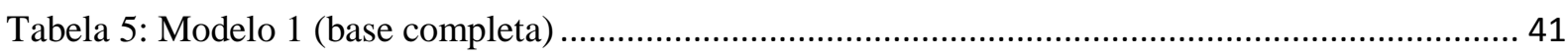

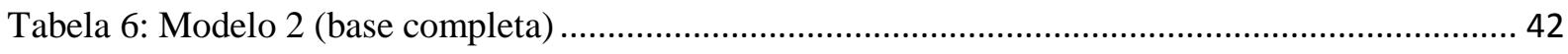

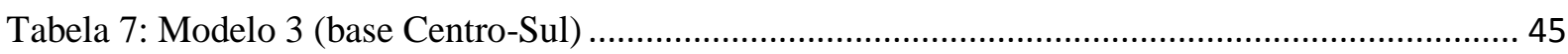

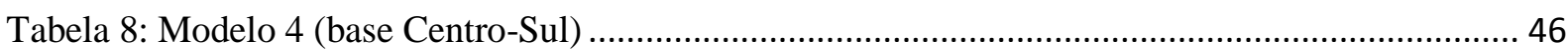

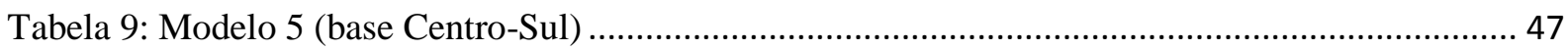

Tabela 10: Eficiência Técnica para CFURH Total - Base Completa.................................................. 48

Tabela 11: Eficiência Técnica para CFURH Total - Base Centro-Sul ............................................... 49

Tabela 12: Eficiência Técnica para CFURH per capita - Base Completa.............................................. 50

Tabela 13: Eficiência Técnica para CFURH per capita - Base Centro-Sul.......................................... 50 


\section{Índice de Figuras}

Figura 1: Compensação Financeira e Royalties de Itaipu ................................................................ 16

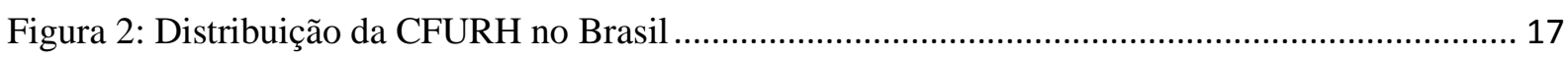

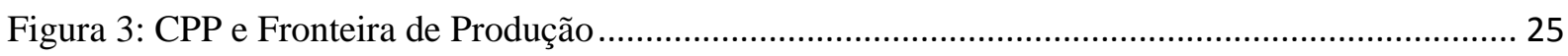

Figura 4: Fronteira de Produção Estocástica ................................................................................ 26 


\section{Introdução}

O Brasil é o quinto maior país do mundo em extensão, com 8515767,049 km², segundo o IBGE, atrás da Rússia, do Canadá, da China e dos Estados Unidos. Este fato contribui para que o país seja conhecido por sua abundância em recursos naturais, como o minério de ferro e o petróleo, assim como a maioria dos países citados acima. Porém, o que diferencia o Brasil dos demais é sua vasta riqueza de recursos hídricos. Além de abrigar a maior bacia hidrográfica do mundo, a Bacia Amazônica, o país possui outras importantes bacias como a do Tocantins-Araguaia, a do rio São Francisco e a dos rios Paraná, Paraguai e Uruguai, onde está instalado o complexo hidroelétrico de Itaipu, que é o segundo maior produtor de energia hidrelétrica do mundo, atrás da usina Três Gargantas na China, de acordo com a Agência Nacional de Energia Elétrica (ANEEL). Reflexo disso é o fato de mais de 75\% da energia elétrica produzida no Brasil entre 2006 e 2010 vir das usinas hidrelétricas, segundo dados do Banco Mundial. No entanto, apesar de ser uma fonte de energia renovável e não emitir poluentes, ela não está isenta de impactos socioambientais. A instalação desse tipo de usina requer inundação de áreas para a construção de barragens, o que gera problemas de realocação das populações que vivem na região, bem como impactos na fauna e flora locais.

Esse impacto existente pela construção de usinas hidrelétricas é remediado através da chamada Compensação Financeira pela Utilização dos Recursos Hídricos - CFURH, instituída inicialmente pela Lei Federal no 7.990, de 28 de dezembro de 1989, alterada pela Lei Federal $n^{\circ}$ 8.001, de 13 de março de 1990, pela Lei Federal ${ }^{\circ}$ 9.648, de 27 de maio de 1998 e pelas Lei Federais no 9.984 e nº 9.993, de 17 e 24 de julho de 2000, conforme a Tabela 1. A CFURH tem como objetivo beneficiar os municípios que abrigam as usinas ou que tenham áreas inundadas por águas dos respectivos reservatórios, e quem paga essas compensações são as próprias hidrelétricas com potência instalada superior a 10 megawatts antes de 1998 e 30 megawatts após este ano. O valor da compensação é de 6,75\% sobre o valor total da energia produzida, multiplicado pela Tarifa Atualizada de Referência (TAR) fixada anualmente pela Agência Nacional de Energia Elétrica e ajustada pelo Índice de Preços ao Consumidor Amplo (IPCA). A TAR reflete o valor médio da energia. Por exemplo, em 2015 foi de R\$ 85,26 por MWh (ANEEL). A repartição desse valor, definida pela Lei Federal $n^{\circ} 9.984 / 2000$ é feita da seguinte forma: dos 6,75\%, 6\% são destinados aos estados, 
municípios, Ministério do Meio Ambiente, Ministério de Minas e Energia e o Fundo Nacional de Desenvolvimento Científico e Tecnológico (FNDCT), recebendo cada um 45\%, 45\%, 3\%, $3 \%$ e $4 \%$ respectivamente. Os outros $0,75 \%$ são encaminhados ao Ministério do Meio Ambiente para a implantação da Política Nacional de Recursos Hídricos e do Sistema Nacional de Gerenciamento de Recursos Hídricos. A aplicação desses recursos por parte dos estados e municípios não é livre. A CFURH não pode ser utilizada para o abatimento de dívidas, a não ser que o credor seja a União, e nem para o pagamento de funcionários.

\section{Tabela 1: Leis Federais relacionadas à CFURH}

\begin{tabular}{|c|c|}
\hline $\begin{array}{l}\text { Lei Federal no } 7.990 \\
\text { (dezembro/1989) }\end{array}$ & $\begin{array}{l}\text { - Primeira lei que regulamenta a compensação financeira pelo resultado da exploração } \\
\text { de petróleo, gás natural, recursos minerais e recursos hídricos; } \\
\text { - Estabelece um valor de } 6 \% \text { sobre o valor da energia produzida, a ser pago pelas } \\
\text { hidrelétricas, aos municípios onde se localizam as instalações da usina ou que tenham } \\
\text { áreas invadidas por águas dos reservatórios; } \\
\text { - Atribui ao Departamento Nacional de Águas e Energia Elétrica (DNAEE) a função } \\
\text { de fixar uma tarifa atualizada de referência (TAR) para efeito de aplicação das } \\
\text { compensações financeiras; } \\
\text { - Isenta as usinas com capacidade nominal inferior a } 10.000 \text { kW de pagarem a } \\
\text { compensação, bem como os autoprodutores; } \\
\text { - Quando mais de um estado ou município for atingido, a distribuição do valor da } \\
\text { compensação será proporcional às áreas inundadas; }\end{array}$ \\
\hline $\begin{array}{l}\text { Lei Federal nº } 8.001 \\
(\operatorname{março/1990)}\end{array}$ & $\begin{array}{l}\text { - Define os percentuais da distribuição da compensação financeira, estabelecida pela } \\
\text { Lei Federal n } 7.990 ; \\
\text { - Estabelece a distribuição dos recursos da seguinte forma: } 45 \% \text { aos estados; } 45 \% \text { aos } \\
\text { municípios; } 8 \% \text { ao DNAEE; } 2 \% \text { ao Ministério da Ciência e Tecnologia; }\end{array}$ \\
\hline $\begin{array}{l}\text { Lei Federal no } 9648 \\
\text { (maio/1998) }\end{array}$ & $\begin{array}{l}\text { - Estabelece a compensação financeira como valor de 6,75\% sobre o valor da energia } \\
\text { elétrica produzida; } \\
\text { - Desse valor, 6\% seriam distribuídos conforme a Lei Federal no } 8.001 \text { e } 0,75 \% \text { seria } \\
\text { destinado ao Ministério do Meio Ambiente, para aplicação da Política Nacional de } \\
\text { Recursos Hídricos do Sistema Nacional de Gerenciamento de Recursos Hídricos; } \\
\text { - Eleva para } 30.000 \mathrm{~kW} \text { a capacidade nominal sujeita à isenção de pagamento; }\end{array}$ \\
\hline $\begin{array}{l}\text { Leis Federais } \\
9.984 \text { e } 9.993 \\
\text { (julho/2000) }\end{array}$ & $\begin{array}{l}\text { - Estabelece uma nova distribuição para os } 6 \% \text { estabelecidos pela Lei Federal no } 8.001 \\
\text { para os recursos, da seguinte forma: } 45 \% \text { aos estados; } 45 \% \text { aos municípios; } 3 \% \text { ao } \\
\text { Ministério do Meio Ambiente; } 3 \% \text { ao Ministério de Minas e Energia; } 4 \% \text { ao Fundo } \\
\text { Nacional de Desenvolvimento Científico e Tecnológico (FNDCT); } \\
\text { - Mantém o mesmo destino aos } 0,75 \% \text { restantes; }\end{array}$ \\
\hline
\end{tabular}


O valor total dessas compensações é considerável. Em 2012, o valor superou 1,72 bilhão de reais e, em 2015, o montante foi de aproximadamente 1,67 bilhão de reais, desconsiderando os royalties de Itaipu, conforme mostra a Figura 1.

Figura 1: Compensação Financeira e Royalties de Itaipu

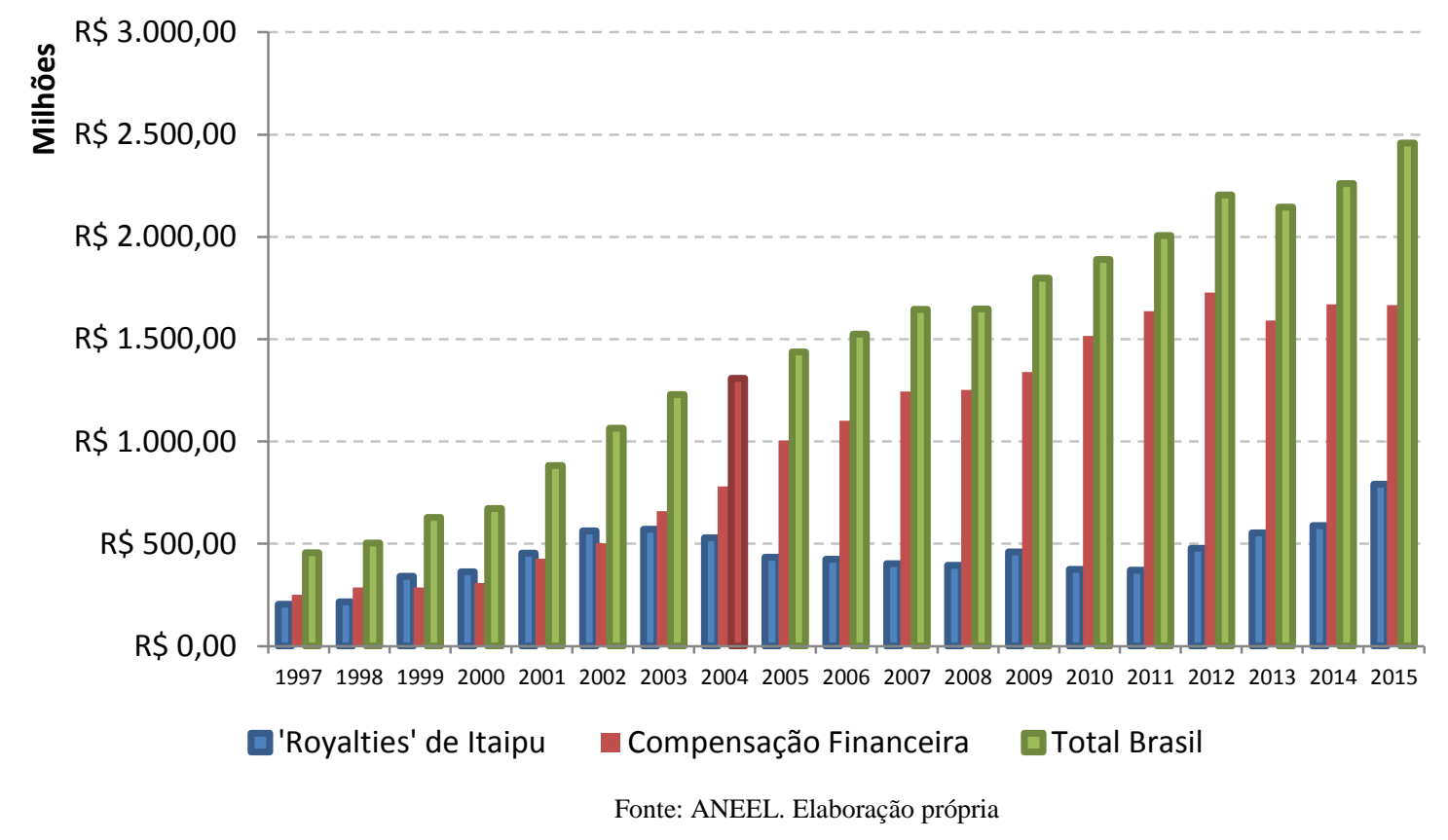

A maior parte desses recursos está no Centro-Sul do país, devido à existência de um maior número de rios e à hidrelétrica de Itaipu. Há uma concentração grande também na região Norte, devido à existência da bacia do Tocantins-Araguaia e da hidrelétrica de Tucuruí, conforme mostra a Figura 2. As áreas mais escuras do mapa representam uma maior concentração de municípios que recebem a CFURH, enquanto que o diâmetro da circunferência representa o volume de recursos recebidos. 
Figura 2: Distribuição da CFURH no Brasil

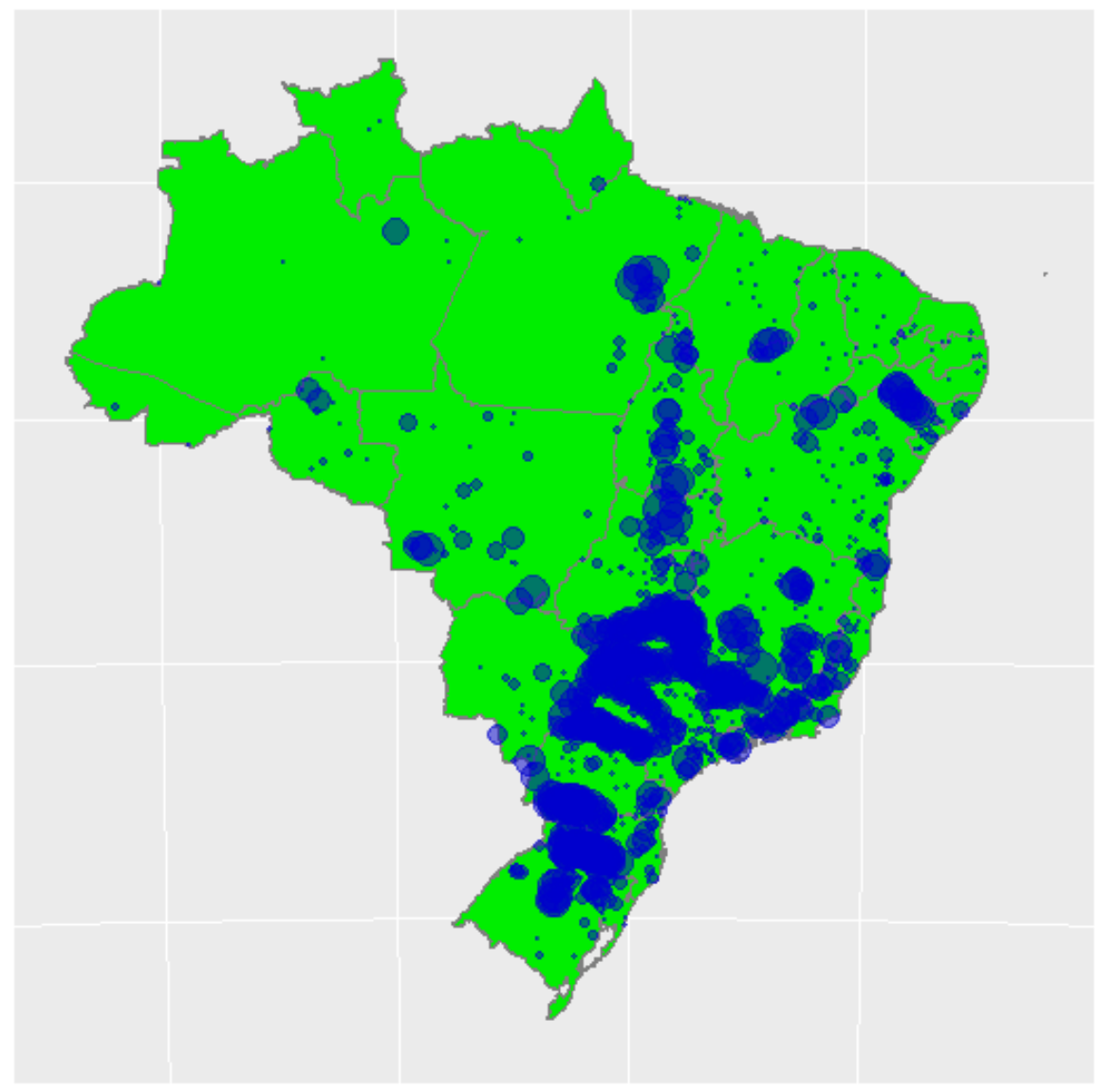

Fonte: Finbra; Elaboração própria.

No entanto, esse valor considerável de compensação financeira suscita um problema amplamente discutido pela literatura econômica: as chamadas transferências verticais geram incentivos para os municípios que as recebem relaxarem o chamado esforço fiscal, ou seja, o empenho para obtenção do montante próxima à carga fiscal estipulada (quociente entre o montante de impostos e contribuições e o PIB), o que resulta em uma menor arrecadação de impostos por parte deles.

\subsection{Recursos Hídricos e a CFURH no Brasil}

Na década de 2010, o Brasil tem passado por um clima menos chuvoso do que a média, o que compromete a geração de energia hidrelétrica. Em 4 de fevereiro de 2014, doze estados, de quatro diferentes regiões ficaram sem energia elétrica, o que foi o último grande apagão no país, segundo o Operador Nacional do Sistema Elétrico (ONS). Além disso, ainda segundo a ONS, o nível de água dos reservatórios atingiu em 2015 os níveis mais baixos desde 2001. Uma das críticas feitas ao governo foi a opção pelas chamadas usinas a fio 
d'água, a exemplo da usina de Belo Monte, que são aquelas que não possuem reservatórios para acumular água nos períodos de estiagem, ou que possuem reservatórios muito pequenos. Segundo dados da ANEEL, das quarenta e duas hidrelétricas leiloadas entre os anos de 2000 e 2012, apenas dez possuem reservatórios. Ainda de acordo com a ANEEL, a usina de Belo Monte, que será a terceira maior do mundo, atrás da hidrelétrica chinesa Três Gargantas $(22,5$ mil MW) e Itaipu (14 mil MW), terá a capacidade total instalada em torno de 11 mil MW, com garantia assegurada de apenas 4,4 mil MW. Por ser do tipo fio d'água, a geração de energia deverá variar conforme a quantidade de água do Rio Xingu, cuja vazão fica bastante reduzida durante os períodos de seca. Estima-se que a CFURH gerada pelo empreendimento possa atingir R \$ 174,8 milhões, a serem distribuídos aos municípios e estado do Pará.

Além do menor potencial de geração de energia, as usinas a fio d'água são mais sujeitas às variações do clima e sofrem mais durante longos períodos de estiagem. Como consequência, a produção de energia fica mais suscetível a choques e, portanto, a renda de recursos hídricos repassada aos municípios que recebem as compensações financeiras pode sofrer grandes variações, de modo que um relaxamento grande do esforço fiscal pode ser perigoso no sentido de deixar um município sem verbas suficientes para investir em educação, saúde e segurança, por exemplo. Ademais, a receita de compensação financeira pela utilização dos recursos hídricos é a principal fonte de recursos de diversos municípios, conforme a Tabela 2, que mostra aqueles que apresentaram as dez maiores razões médias de CFURH/Receita Tributária entre 2007 e 2012. A média de todos os 5552 municípios é de $9,76 \%$.

Tabela 2: CFURH/Receita Tributária

\begin{tabular}{ccccc}
\hline Município & UF & Média RT (R\$) & Média CFURH (R\$) & Média CFURH/RT \\
\hline Grupiara & MG & $124.565,54$ & $2.770 .347,79$ & $2376,81 \%$ \\
Douradoquara & MG & $109.074,61$ & $1.671 .666,82$ & $1778,31 \%$ \\
Porto Barreiro & PR & $167.985,31$ & $1.955 .508,73$ & $1268,57 \%$ \\
Novo Repartimento & PA & $2.418 .510,05$ & $25.194 .545,64$ & $1198,70 \%$ \\
Campinaçu & GO & $315.056,39$ & $3.150 .782,72$ & $1074,15 \%$ \\
Cascalho Rico & MG & 346.859 & $2.819 .015,82$ & $884,50 \%$ \\
Goianésia do Pará & PA & $1.214 .197,44$ & $9.367 .987,05$ & $835,52 \%$ \\
Mariano Moro & RS & $213.950,92$ & $1.409 .923,92$ & $799,86 \%$ \\
Celso Ramos & SC & 282432,04 & $2.056 .196,67$ & $761,01 \%$ \\
Pedrinópolis & MG & $268.090,69$ & $1.849 .283,41$ & $692,08 \%$ \\
\hline
\end{tabular}

Fonte: Finbra. Elaboração própria 


\subsection{Esforço Fiscal no Brasil}

A análise do esforço tributário, ou seja, de arrecadação de impostos, ganhou importância durante a década de 1990, com o aumento das transferências entre as esferas de governo, através do Fundo de Participação dos Estados (FPE) e do Fundo de Participação dos Municípios (FPM). Atualmente, $21,5 \%$ da receita do Imposto de Renda (IR) e do Imposto sobre Produtos Industrializados (IPI), deduzidas as restituições e os incentivos fiscais, vão para o FPE, e 23,5\% do mesmo valor vai para o FPM, segundo o Ministério da Fazenda. Com o aumento do volume dessas transferências, a maioria dos estados e municípios relaxou seu esforço arrecadatório, e passou a praticar uma política fiscal expansionista, conforme mostra Cossio (1998). O principal resultado deste processo é o endividamento dos estados e municípios junto à União.

A Secretaria do Tesouro Nacional (STN) calcula a razão entre Dívida Consolidada Líquida (DCL) e Receita Corrente Líquida (RCL) para estados e municípios. De acordo com o Manual de Demonstrativos Fiscais (MDF) da STN, a DCL representa o montante da Dívida Consolidada (DC), deduzido o saldo relativo a haveres financeiros. A DC, por sua vez, corresponde ao montante total das obrigações financeiras assumidas: pela realização de operações de crédito com a emissão de títulos públicos, para a amortização em prazo superior a 12 meses; pela realização de operações de crédito em virtude de leis, contratos, convênios ou tratados, com prazo superior a 12 meses; com os precatórios judiciais emitidos a partir de 5 de maio de 2000 e não pagos durante a execução do orçamento; pela realização de operações de crédito de prazo inferior a 12 meses, que tenham constado como receitas no orçamento. Já a RCL é o somatório das receitas tributárias, de contribuições, patrimoniais, agropecuárias, industriais, de serviços, transferências correntes o outras receitas do ente da Federação, deduzidos alguns itens explicitados na Lei de Responsabilidade Fiscal (LRF). O limite da relação DCL/RCL está previsto na Resolução Federal n ${ }^{0} 40$ do Senado Feral, de 20 de dezembro de 2001 da seguinte forma: a razão deve ser inferior a 2,0 no caso dos estados e do Distrito Federal e inferior a 1,2 no caso dos municípios. Em 2015, apenas o Rio Grande do Sul teve uma razão superior a 2,0. No entanto, os estados com maior PIB estão próximos ao limite: Minas Gerais apresentou razão de 1,99 no último quadrimestre de 2015; Rio de Janeiro apresentou razão de 1,98 e São Paulo de 1,68, sendo que todos os estados apresentaram trajetória crescente durante o ano de 2015. Em relação aos municípios, dos 1259 municípios 
com dados disponíveis pela STN, 717 deles, ou seja, 56,95\% apresentaram razão superior aos 1,2 determinados pelo Senado no terceiro quadrimestre de 2015, sendo Nazaré da Mata (PE) o município com a maior razão, igual a 221,54.

Além do FPM e do FPE, outras transferências verticais também induzem ao relaxamento do esforço fiscal, dentre elas, as compensações financeiras. Há diversos trabalhos sobre os impactos da compensação financeira pela exploração dos recursos minerais e do petróleo (os chamados royalties) sobre a arrecadação municipal, que serão citados ao longo desta dissertação, mas há poucos sobre o impacto da compensação financeira pela exploração dos recursos hídricos, e nenhum conhecido que utilize a metodologia de fronteira estocástica.

\subsection{Objetivo}

Esta dissertação de mestrado em teoria econômica tem como objetivo principal avaliar o impacto da CFURH sobre a arrecadação tributária dos municípios que recebem essas compensações. Em outras palavras, procura-se responder se há ou não certa acomodação por parte dos municípios que recebem rendas advindas dos recursos hídricos, o que resultaria em uma redução do esforço fiscal. Para isso, será utilizada a técnica de fronteira estocástica, introduzida simultaneamente por Aigner, Lovell \& Schimidt e Meeusen \& Van Den Broeck, ambos em 1977, para estimar uma função de produção ótima de arrecadação de imposto, para depois avaliar como que o recebimento da CFURH afeta essa eficiência arrecadatória, assim como Postali (2015) fez para avaliar o impacto dos royalties do petróleo no esforço fiscal.

Esta dissertação se divide em mais quatro capítulos, além da introdução: no segundo capítulo, será feita uma breve revisão da literatura sobre recursos naturais, transferências verticais e esforço fiscal e sobre aplicações da metodologia de fronteira estocástica. No terceiro capítulo, será apresentada a técnica de fronteiras estocásticas e serão apresentados os dados utilizados. O quarto capítulo conterá os resultados obtidos. Por fim, o quinto capítulo conclui o que foi feito nesta dissertação. 


\section{Revisão da Literatura}

\subsection{Recursos Naturais e Compensações Financeiras}

Explorar um recurso natural, seja este renovável ou não, pode exigir um alto custo inicial. A existência de incentivos para que empresas tomem o risco de empreendimentos desse tipo geralmente é garantida pelo governo, de forma que este fornece uma licença de exploração a uma determinada empresa, que se compromete a investir na extração do recurso. O governo recebe em contrapartida uma compensação financeira pela permissão desta exploração do recurso. Leal e Serra (2003) definem os chamados royalties como "o fluxo de pagamentos aos proprietários de um ativo não renovável (material ou imaterial) que o cede para ser explorado, usado ou comercializado por outras empresas ou indivíduos".

No caso dos recursos não renováveis, Friedmann e Montalvão (2003) e Serra (2003) chamam atenção para a existência de um problema intergeracional: como são finitos, a extração do recurso no presente impossibilita sua extração futura. A compensação paga seria então uma forma de elevar o custo da extração hoje e permitir uma transferência de recursos entre gerações. Além disso, deve-se a Hartwick (1977) a relação entre rendas de recursos não renováveis e sustentabilidade econômica, ao mostrar que o montante deve ser investido em ativos físicos, de modo a manter o estoque de capital constante frente à redução do estoque do recurso.

Embora os recursos hídricos sejam renováveis, é possível traçar um paralelo com essa literatura de recursos não renováveis. Hensengerth et al (2012) descrevem as externalidades geradas pela construção de uma barragem para a produção de energia elétrica, como mudanças de curso e mudanças no regime de sedimentação. Wildi (2010) cita mais impactos ambientais como modificações nas propriedades físico-químicas do rio como a salinidade e o nível de oxigênio da água, bem como impactos no ecossistema local, com perda de parte da fauna e flora e mudanças no habitat dos seres vivos daquela região. Fearnside (1999) descreve os impactos sociais da construção da usina hidrelétrica de Tucuruí no Brasil, como destruição de comunidades ribeirinhas e indígenas e aumento da incidência de doenças como a malária. Resumindo, embora a produção de energia hidrelétrica venha de um recurso renovável, ela gera impactos permanentes aos municípios que recebem as usinas ou que são afetadas pela 
construção de barragens e reservatórios de água. Por esse motivo, estados e municípios recebem a Compensação Financeira pela Utilização de Recursos Hídricos (CFURH), que se equivale aos royalties do petróleo e à Compensação Financeira pela Exploração Recursos Minerais (CFEM).

\subsection{Transferências Verticais e Esforço Fiscal}

Posto isso, torna-se interessante discutir outra questão: se essas compensações causam algum tipo de ineficiência fiscal, no sentido de que municípios que recebem esses recursos relaxam seus esforços de arrecadação. A relação entre federalismo fiscal, impostos e gastos é bastante discutida pela literatura econômica. Segundo Oates (1999), países organizados dessa maneira têm como objetivo nivelar a capacidade fiscal entre suas regiões. Ainda segundo o autor, o mecanismo mais comum adotado pelos países é o de compensar as localidades de forma inversamente proporcional à sua capacidade fiscal. Além disso, cada unidade da Federação pode ter diferentes níveis ótimos de bens públicos, no qual seu custo marginal é igual a seu benefício marginal. Deste modo, torna-se possível maximizar o bem-estar social de acordo com o nível ótimo de cada região. Entretanto, Dahlby (2011) mostra que transferências intergovernamentais criam um efeito preço além do efeito renda, ao permitir que governos locais reduzam sua arrecadação, de modo a reduzir o custo marginal dos recursos públicos, ainda provendo o mesmo nível de serviços públicos, o que explica em parte o chamado "flypaper effect", ou seja, quando uma unidade monetária advinda de transferências apresenta um efeito maior sobre o gasto público do que um incremento equivalente da renda privada da população local. Sanguinetti e Tommasi (2004) mostram que transferências verticais para ajudar regiões com dificuldades orçamentárias criam uma situação de moral hazard ao suavizar as restrições orçamentárias enfrentadas por elas.

Há diversos estudos que têm como objetivo avaliar se transferências verticais reduzem o esforço fiscal em alguns locais. Buettner (2006) avalia se isso ocorreu na Alemanha, após uma mudança na regra de distribuição de recursos para equalizar a capacidade fiscal de suas regiões. $\mathrm{O}$ autor conclui que um aumento nesses recursos levou a uma redução nas alíquotas de imposto locais. Dahlberg et al. (2008) fazem um estudo parecido na Suécia, mas não encontram evidência de redução nas alíquotas locais de impostos. Entretanto, os autores 
mostram que os gastos das províncias que receberam a maior parte das transferências se elevaram (o chamado flypaper effect). Aragon e Gayoso (2005) avaliam o papel do desincentivo ao esforço fiscal devido às transferências do governo nas cidades do Peru, utilizando um painel de dados. O trabalho encontrou evidências de uma relação negativa entre essas transferências e o esforço fiscal, de modo que o efeito final pode ser uma maior dependência em relação ao governo central e um aumento do déficit fiscal agregado. Em relação ao Brasil, Cossio (1998) encontra evidência de que municípios mais dependentes das transferências são os que mais tendem a reduzir seu próprio esforço fiscal, o que configura uma situação ainda mais grave. Ribeiro e Shikida (2000) obtêm conclusões semelhantes em relação aos municípios de Minas Gerais. Postali e Rocha (2009) e Postali (2015) encontram evidência, a partir de metodologias distintas, de uma redução do esforço fiscal nos municípios que recebem os royalties do petróleo. Carnicelli e Postali (2012) concluem que há evidências de menor arrecadação por parte do grupo de municípios que recebem royalties do petróleo através de uma análise de propensity score com efeitos fixos.

Em relação aos impactos das rendas geradas pela exploração de recursos naturais no crescimento e no bem-estar das localidades, Postali (2009) avalia que os maiores beneficiários dos royalties do petróleo cresceram menos do que os não beneficiários. Em relação ao desenvolvimento local, Postali e Nishijima (2011) analisam o Índice FIRJAN de Desenvolvimento Municipal (IFDM), que leva em consideração as áreas de emprego e renda, educação e saúde. A conclusão dos autores é de que os impactos não se mostraram significativos em relação à educação e à saúde, e houve impacto negativo em relação ao mercado de trabalho formal. Entretanto, Postali e Nishijima (2013) encontram evidência de um impacto positivo em relação ao acesso à água, à eletricidade, à coleta de lixo e à redução do analfabetismo ao longo de vinte anos nos municípios beneficiados por esses recursos. Caselli e Michaels (2009) utilizam o produto gerado pelo petróleo para analisar os efeitos dos royalties do petróleo. Os autores concluem que a abundância de petróleo aumenta os gastos dos municípios, mas que as transferências sociais, a provisão de bens públicos, infra-estrutura e renda familiar aumentam menos do que o esperado devido a esse incremento nos gastos públicos. Por fim, os autores utilizam dados da mídia brasileira e da polícia federal para concluir que um produto extremamente elevado derivado da exploração de petróleo aumenta o índice de atividades ilegais associadas aos prefeitos. Monteiro e Ferraz (2010) analisam a maneira como os municípios gastam os royalties do petróleo recebidos e o impacto dessa 
renda nas eleições locais. Os autores associam esses recursos a um elevado número de empregados municipais, mas não encontram impactos significantes na renda familiar, infraestrutura, segurança e saúde.

\subsection{Fronteira Estocástica}

A técnica de fronteira estocástica é amplamente usada para mensurar ineficiências na produção, e é aplicada em diversas áreas. Battese e Coelli (1992) utilizam dados em painel para medir ineficiências nos campos de arroz da Índia. Battese e Corra (1977) estimam uma fronteira de produção para a zona de pastoreio no leste australiano. No Brasil, em relação ao uso da técnica na área agrícola, Imori (2011) utiliza dados do Censo Agropecuário de 2006 para analisar a eficiência técnica dos estabelecimentos agropecuários brasileiros. Igliori (2005) utiliza o modelo proposto por Battese e Coelli (1995) para avaliar a eficiência técnica da agricultura e criação de gado no Brasil. Postali (2015) utiliza a técnica para estimar uma fronteira de produção ótima de impostos dos municípios e analisar o impacto do recebimento de royalties do petróleo na arrecadação de cada um deles, com o objetivo de investigar um possível relaxamento do esforço fiscal.

Embora os recursos oriundos da exploração de recursos naturais como o petróleo tenham outra regra de compensação, os municípios beneficiados estão sujeitos ao mesmo tipo de ineficiência gerado pelas transferências verticais. 


\section{Metodologia e Dados}

\subsection{Eficiência Produtiva}

Para a produção de qualquer bem, é necessário transformar os insumos em produtos. Há diversas formas de realizar esta transformação, e todas podem ser representadas por um conjunto de possibilidade de produção (CPP), conforme a Figura 2 abaixo.

Figura 3: CPP e Fronteira de Produção

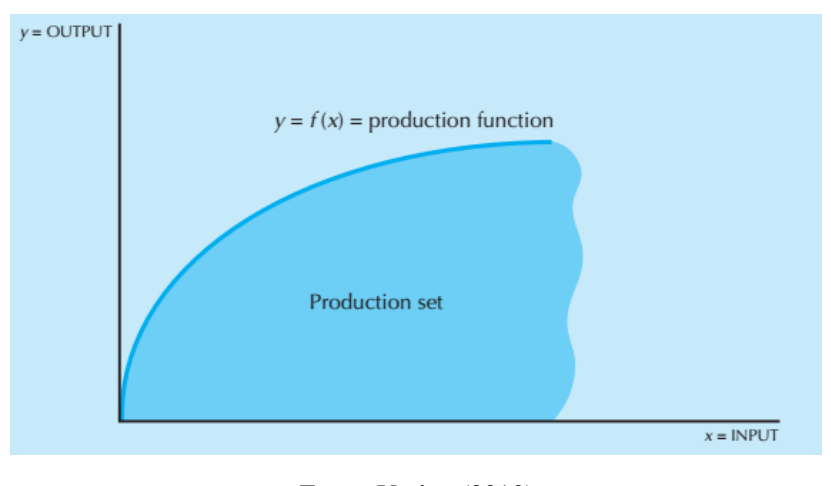

Fonte: Varian (2010)

Na figura acima, qualquer par ordenado $(x, y) \in C P P$ representa uma maneira factível de transformar os insumos $x$ em produto $y$, mas de forma limitada por uma restrição tecnológica, no caso a fronteira de produção $y=f(x)$, que indica a quantidade máxima de produto que pode ser obtida através de uma determinada quantidade de insumos. Desse modo, qualquer ponto localizado sobre a fronteira de produção é considerado eficiente, e qualquer ponto dentro dessa fronteira é ineficiente, ou seja, é possível obter uma maior quantidade de produto a partir da mesma quantidade de insumo.

Desvios em relação à fronteira de produção refletem falhas na otimização do processo de produção, ou seja, o grau de eficiência relativa pode ser medido pela distância vertical entre um ponto na CPP e a fronteira de produção, como ilustrado na Figura 3. Como esta é desconhecida, ela deve ser estimada. Uma das abordagens para estimar o grau de eficiência de cada uma das firmas consiste em estimar a fronteira de produção por meios econométricos, os quais se classificam em modelos de fronteira determinística e modelos de fronteira estocástica (Kumbhakar e Lovell, 2000). Nesta dissertação, a estimação será feita através do método da 
fronteira estocástica, introduzido simultaneamente por Aigner, Lovell \& Schimidt (1977) e Meeusen \& Van Den Broeck (1977).

Figura 4: Fronteira de Produção Estocástica

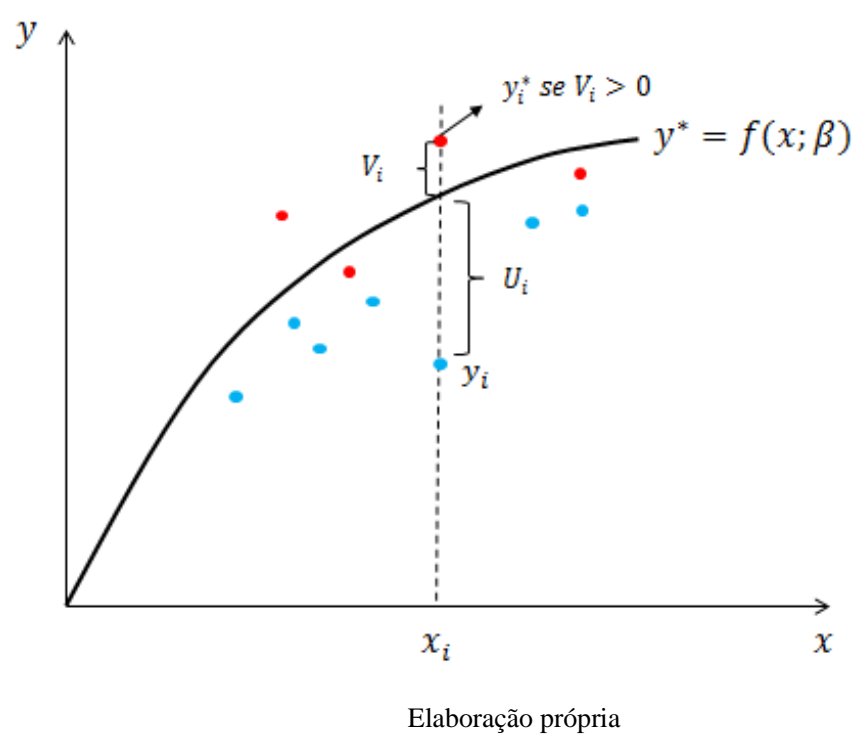

\subsection{Modelo Paramétricos Anteriores}

Os modelos anteriores aos de fronteira estocástica para a estimação de fronteiras de produção foram utilizados por Aigner e Chu (1968), Afriat (1972) e Richmond (1974). Eles partem de uma função que fornece o produto máximo dado um certo nível de insumo:

$$
y_{i}=f\left(x_{i} ; \beta\right), \quad i=1,2, \ldots, n
$$

em que $y_{i}$ é o produto, $x_{i}$ é o vetor de insumos e $\beta$ é o vetor de parâmetros a ser estimado.

Aigner e Chu (1968) sugerem a estimação da equação (1) através da seguinte minimização:

$$
\min \sum_{i}\left|y_{i}-f\left(x_{i} ; \beta\right)\right|
$$

sujeito à restrição $y_{i} \leq f\left(x_{i} ; \beta\right)$, o que é um caso de programação linear, ou 


$$
\min \sum_{i}\left[y_{i}-f\left(x_{i} ; \beta\right)\right]^{2}
$$

sujeito à mesma restrição, de modo a tornar um caso de programação quadrática.

O grande problema desta abordagem é o fato de ela ser extremamente sensível a outliers. Outro problema ocorre na justificativa de observações acima da fronteira, o que é incompatível com a ideia de que o produto é máximo. Além disso, os métodos de programação matemática levam a estimadores cujas propriedades estatísticas são desconhecidas. Schmidt (1976) inclui no modelo um termo de erro:

$$
y_{i}=f\left(x_{i} ; \beta\right)+\varepsilon_{i}, i=1,2, \ldots, n
$$

onde $\varepsilon_{i} \leq 0$.

Sob alguma hipótese sobre a distribuição do erro, o modelo pode ser estimado por máxima verossimilhança. Se assumirmos que $\varepsilon_{i}$ tem distribuição exponencial, recaímos no caso de programação linear. Se assumirmos uma distribuição half-normal para o termo de erro, recaímos no caso de programação quadrática. No entanto, as condições de regularidade para a estimação por máxima verossimilhança não são atendidas, visto que, como $y_{i} \leq$ $f\left(x_{i} ; \beta\right)$, o range da variável aleatória $y$ depende dos parâmetros a serem estimados, de modo a invalidar a distribuição assintótica dos parâmetros (Aigner, Lovell \& Schmidt, 1977).

\subsection{Modelo de Fronteira Estocástica - Cross-Section}

O primeiro modelo de fronteira estocástica, proposto por Aigner, Lovell \& Schimidt (1977) considera uma cross-section $\operatorname{com} i=1, \ldots, I$ firmas e é representado pela seguinte equação:

$$
y_{i}=f\left(X_{i} \beta\right)+V_{i}-U_{i}
$$

onde $X_{i}$ é um vetor de insumos, $y_{i}$ é uma medida do produto e $\beta$ é o vetor de parâmetros a serem estimados, e captura a variação do produto decorrente de uma variação nos insumos. O termo de erro é composto por duas partes. A primeira, $V_{i}$, é um componente aleatório fora do controle das firmas, e é independente identicamente distribuído (i.i.d.), de modo que $V_{i} \sim N\left(0, \sigma_{v}^{2}\right)$. A segunda, $U_{i}$, reflete o fato de que o produto é limitado 
superiormente pela fronteira de produção e possui uma distribuição truncada em $U_{i} \geq 0$. Usualmente, assume-se que $U_{i}$ possui half-normal distribution, de modo que $U_{i} \sim N^{+}\left(\mu, \sigma_{u}^{2}\right)$. É necessária a hipótese de que $\operatorname{Cov}\left(V_{i}, U_{i}\right)=0$.

A medida de eficiência pode ser obtida através do termo $U_{i}$ da seguinte forma:

$$
T E=\frac{y_{i}}{E\left[y_{i} \mid U_{i}=0\right]}=\frac{y_{i}}{f\left(X_{i}, \beta\right)}
$$

Como $U_{i} \geq 0$, então $T E \in(0,1]$. Quanto maior a distância de $U$ à fronteira de produção, mais próxima de zero estará a eficiência técnica $(T E)$, e quando $U \rightarrow 0, T E \rightarrow 1$. Além disso, o componente aleatório $V$ pode impactar tanto positivamente quanto negativamente na eficiência, e pode variar para uma mesma firma ao longo do tempo. A estimação proposta é por máxima verossimilhança, e a função de máxima verossimilhança é derivada por Aigner, Lovell \& Schmidt (1977).

\subsection{Modelo de Fronteira Estocástica - Painel}

Battese e Coelli (1995) estenderam o modelo de fronteira estocástica para dados em painel, no qual os termos de ineficiência são parametrizados através de um conjunto de variáveis explicativas. O modelo é dado pelas seguintes equações:

$$
y_{i t}=\exp \left(X_{i t} \beta+V_{i t}-U_{i t}\right)
$$

onde $y_{i t}$ denota a produção da t-ésima observação $(t=1, \ldots, T)$ para a i-ésima firma $(i=$ $1, \ldots, I), x_{i t}$ é um vetor $1 x k$ com os insumos da produção e outras variáveis explicativas, $\beta$ é um vetor $k x 1$ de parâmetros a ser estimados e $V_{i t} \sim N\left(0, \sigma_{v}^{2}\right)$ (i.i.d.). Além disso,

$$
U_{i t}=Z_{i t} \delta+W_{i t}
$$

onde $U_{i t}$ contém componentes aleatórios com distribuição normal truncada no zero, representando a ineficiência técnica, ou seja, $U_{i t} \sim N\left(Z_{i t} \delta, \sigma_{v}^{2}\right)$, sendo $Z_{i t}$ as variáveis que 
explicam a ineficiência técnica e $\delta$ é um vetor de coeficientes a ser estimado. Por fim, $W_{i t} \sim N\left(0, \sigma^{2}\right)$ é uma variável aleatória truncada no ponto $-Z_{i t} \delta$. Além disso, é necessária a hipótese de que $U_{i t}$ e $V_{i t}$ sejam não correlacionados.

Segundo Battese e Coelli (1995), ambas as equações devem ser estimadas simultaneamente, através do método da máxima verossimilhança, de modo a obter os parâmetros da fronteira de produção estocástica $(\beta)$ e os coeficientes da equação de ineficiência $(\delta)$. Para isso, os autores seguem Battese e Coelli (1993), que substituem $\sigma_{v}^{2}$ e $\sigma$ por $\sigma_{s}^{2}=\sigma^{2}+\sigma_{v}^{2}$ e fazem $\gamma=\sigma^{2} / \sigma_{s}^{2}$. Battese e Coelli (1993) também apresentam a função de máxima verossimilhança e suas derivadas em relação aos parâmetros $\left(\beta, \delta, \sigma_{s}^{2}, \gamma\right)$.

A eficiência técnica $(T E \in(0,1])$ de cada município $i$ no ano $t$ pode ser definida pela razão $\frac{y_{i t}}{y_{i t}^{*}}$, onde $y_{i t}^{*}$ é a produção estimada na fronteira eficiente (quando $U_{i t}=0$ ). Temos:

$$
T E_{i t}=\frac{\exp \left(X_{i t} \beta+V_{i t}-U_{i t}\right)}{\exp \left(X_{i t} \beta+V_{i t}\right)}=\exp \left(-U_{i t}\right)=\exp \left(-Z_{i t} \delta-W_{i t}\right)
$$

\subsection{Discussões Sobre a Metodologia de Fronteiras Estocásticas}

\subsubsection{Distribuição do Termo de Erro}

A escolha da distribuição do termo de erro $U_{i}$ é amplamente discutida na literatura. Meeusen \& Van Den Broeck (1977) e Aigner, Lovell \& Schmidt (1977) apresentaram a verossimilhança e alguns resultados utilizando a distribuição exponencial para o termo de ineficiência. Além disso, Aigner, Lovell \& Schmidt (1977) apresentam a distribuição de probabilidade de $\varepsilon$ sob a hipótese de que $v \sim N\left(0, \sigma_{v}^{2}\right)$ e $u$ é o valor em módulo de uma variável que é independente de $v$ e com distribuição $u \sim N^{+}\left(0, \sigma_{u}^{2}\right)$. A função de $\log$ verossimilhança para uma amostra com $\mathrm{N}$ observações é dada por:

$$
\ln L=-\left(\frac{N}{2}\right)\left(\ln 2 \pi+\ln \sigma^{2}\right)+\sum_{i}\left[\ln \Phi\left[-\frac{\varepsilon_{i} \lambda}{\sigma}\right]-\frac{1}{2}\left(\frac{\varepsilon_{i}}{\sigma}\right)^{2}\right]
$$


onde

$\Phi($.$) representa a função de distribuição acumulada de uma normal-padrão e$ $\sigma^{2}=\sigma_{v}^{2}+\sigma_{u}^{2} \mathrm{e} \lambda=\sigma_{u} / \sigma_{v}$

Uma vez estimados os parâmetros, Jondrow et al (1982) sugerem uma estimação do termo de ineficiência específico para a firma $i$ :

$$
E\left[u_{i} \mid v_{i}-u_{i}\right]=E\left(u_{i} \mid \varepsilon_{i}\right)=\frac{\sigma \lambda}{1+\lambda^{2}}\left[\frac{\phi\left[\frac{\varepsilon_{i \lambda}}{\sigma}\right]}{\Phi\left[\frac{\varepsilon_{i} \lambda}{\sigma}\right]}-\frac{\varepsilon_{i} \lambda}{\sigma}\right]
$$

Posteriormente, em 1980, Stevenson sugeriu uma distribuição Normal truncada e, em 1990, Greene sugeriu o uso da distribuição Gama (Kumbhakar \& Lovell, 2003), bem como derivou a função de máxima verossimilhança sob esta distribuição. Greene (1990) ainda utiliza dados da indústria de eletricidade nos Estados Unidos para estimar uma fronteira de custo, ao invés de uma fronteira de produção, e compara os resultados sob as distribuições half-normal, normal truncada, gamma, exponencial e os mínimos quadrados corrigidos (COLS), obtendo resultados muito próximos, com exceção do método COLS. O autor ainda conclui que as ineficiências estimadas sob a distribuição gamma são, em geral, um pouco menores do que aquelas estimada sob a distribuição half-normal.

Neste trabalho, foi utilizada a distribuição Half-Normal, dado que ela é mais amplamente empregada na literatura de fronteira estocástica.

\subsubsection{Forma Funcional da Função de Produção}

Outro ponto de discussão da metodologia de fronteiras estocásticas se refere à especificação da função de produção. Sauer et al (2006) discutem o trade-off entre flexibilidade e inconsistência teórica na escolha da especificação. Na metodologia de fronteira estocástica, utiliza-se geralmente a função de produção Cobb-Douglas ou a Translog, sendo esta última mais flexível, mas, no entanto, pode levar a resultados sem consistência teórica. 
De acordo com Lau (1978 e 1986), alguns critérios devem ser verificados antes da escolha de uma forma algébrica para expressar uma relação econômica. O primeiro é a consistência teórica, ou seja, a forma funcional escolhida deve apresentar todas as propriedades desejáveis a um conjunto de possibilidade de produção, ou seja, a equação (10) deve ter valor único, apresentar monotonicidade para cada insumo, produtividade marginal decrescente para cada insumo e ser quasicôncava, de modo que o conjunto de insumos seja convexo. No entanto, esse critério não basta para indicar a forma funcional adequada. $\mathrm{O}$ segundo critério é o domínio de aplicação, ou seja, do conjunto de valores das variáveis independentes $x_{i}$ dado um vetor de parâmetros $\beta_{i}$.

$$
y_{j}=f\left(x_{i j}, \beta_{i}\right)+\varepsilon_{j}
$$

Se, para um dado $\beta_{i}$ a forma algébrica $f\left(x_{i}, \beta_{i}\right)$ é teoricamente consistente sobre o conjunto do domínio de aplicação, ela é globalmente teoricamente consistente sobre aquele conjunto. O terceiro critério é o de flexibilidade. Uma forma funcional flexível é capaz de aproximar de uma forma arbitrária, mas teoricamente consistente, um comportamento econômico, através da escolha apropriada de parâmetros. O quarto critério é o da facilidade computacional, que implica as propriedades de linearidade nos parâmetros, representatividade explícita, uniformidade e parcimônia. O quinto critério é o da conformidade factual, ou seja, que a forma funcional deve ser consistente com os fatos empíricos do problema econômico a ser modelado.

Sauer et al (2006) dizem que uma forma funcional globalmente teoricamente consistente e flexível pode ser considerada uma representação adequada do conjunto de possibilidade de produção. Ademais, a consistência teórica local e flexibilidade de formas funcionais podem ser consideradas como uma aproximação diferencial de ordem $i$ das verdadeiras possibilidades de produção. Portanto, a forma translog é considerada uma aproximação diferencial de segunda ordem das verdadeiras possibilidades de produção. Para checar a consistência teórica em um determinado ponto, é necessário calcular o Hessiano neste ponto e, para checar a consistência global, é necessário calcular o Hessiano em cada ponto. 
Nesta dissertação, foram estimados modelos utilizando tanto uma função de produção Cobb-Douglas quanto uma Translog. Como a primeira forneceu melhores resultados, consistentes com uma função de produção, foi descartado o uso da função Translog.

\subsection{Metodologias Alternativas para Análise de Eficiência}

Alternativamente à técnica de fronteiras estocásticas para a análise de eficiência técnica, outra metodologia bastante comum é a DEA (Data Envelopment Analysis), desenvolvida por Charnes et al (1978), a qual utiliza programação linear para avaliar o grau de eficiência produtiva das chamadas decision making units (DMUs). A DEA permite otimizar individualmente cada uma das observações em relação às demais, de modo a formar uma fronteira de eficiência. As medidas de eficiência técnica são então calculadas em relação à essa fronteira eficiente.

A DEA, por ser uma técnica não paramétrica, não exige que sejam feitas hipóteses sobre a distribuição do termo de erro e nem sobre uma forma funcional da função de produção. Além disso, a DEA permite múltiplos insumos e produtos. Por outro lado, as técnicas paramétricas permitem testes de hipótese, bem como a inclusão de variáveis de controle na equação de ineficiência, por exemplo, no caso da fronteira estocástica. Por fim, é importante destacar que a DEA é muito sensível a outliers, o que é comum no caso da CFURH.

\subsection{Dados}

Podemos aplicar a metodologia de fronteira estocástica considerando que cada município possui uma função de produção de impostos, que depende de fatores que estão sob seu controle $(U)$ e que não estão $(V)$. A eficiência técnica serve como medida da distância do município para a fronteira e quanto mais próxima desta, maior é o esforço fiscal. Além da função de produção, a segunda equação seria a de ineficiência, que deve conter variáveis que afetam a ineficiência $(U)$, a exemplo da CFURH.

Para a função de produção, é necessária uma variável que represente o estoque de capital e outra que represente o de trabalho. Como esses dados não estão disponíveis, serão usados os gastos com capital e com pessoal como proxy para essas variáveis. Serão rodados 
modelos para duas bases diferentes: a primeira será a base completa, incluindo 5552 municípios de todos os estados brasileiros; a segunda será a base considerando 3321 municípios do Centro-Sul do país. O motivo para isso é tentar ganhar precisão e robustez nos resultados, dado que a base do Finbra (Finanças do Brasil) é preenchida por responsáveis dos próprios municípios, podendo conter considerável erro de medida, sobretudo nos municípios pequenos ou pouco desenvolvidos, que estão concentrados mais ao norte do Brasil. Os dados utilizados vão de 2007, ano mais recente em que o Finbra fez a última subdivisão em categorias de algumas das variáveis utilizadas aqui, até 2012, último dado do PIB municipal disponível pelo Instituto Brasileiro de Geografia e Estatística (IBGE).

As variáveis dependentes a serem utilizadas serão a receita tributária total para a base completa, e a arrecadação municipal do IPTU para a base Centro-Sul, uma vez que a maioria dos municípios da região é urbana, e este é um dos principais impostos dentre aqueles que são arrecadados diretamente pelos municípios, e o que mede melhor a questão do esforço fiscal ${ }^{1}$. Além disso, o IPTU é um imposto mais robusto a ciclos econômicos do que o Imposto Sobre Serviços (ISS), e a receita tributária total, que inclui, além do IPTU, o ISS e o ITBI (Imposto sobre Transmissão de Bens e Imóveis Inter vivos), além de demais taxas. Por fim, o IPTU é um imposto mais difícil de sonegar do que o ISS, reduzindo possíveis erros de medida.

Tanto os dados de impostos quanto os de gastos com capital e trabalho em âmbito municipal podem ser obtidos do Finbra. Como o IPTU depende do grau de urbanização do município, será utilizada a porcentagem do PIB agrícola sobre o PIB total do município como controle na equação de ineficiência. Além disso, outras variáveis a serem testadas na equação de ineficiência são a população, o PIB e o PIB per capita, transferências de diversas origens, a cota do FPM (Fundo de Participação dos Municípios), bem como a CFURH, outros tipos de compensação financeira (Compensação Financeira pela Exploração de Recursos Minerais CFEM e royalties do petróleo) e dummies de ano e de partido político. Além do Finbra, foi usada outra fonte de dados para o PIB municipal e agrícola, que foram retirados do IBGE. As estatísticas descritivas dos dados seguem nas Tabelas 3 e 4. Pode-se ver que, para as variáveis dependentes, ou seja, a receita tributária e o IPTU, os valores médios e de cada quartil são

\footnotetext{
${ }^{1}$ Um exemplo é o mapeamento aéreo feito em cidades do interior de São Paulo, como Campinas, Itu e Sorocaba, entre 2013 e 2015, segundo a Secretaria Municipal de Planejamento e Desenvolvimento Urbano (Seplan) e a Secretaria da Fazenda dos municípios citados. No caso de Sorocaba, a estimativa era a de arrecadar 25\% a mais em 2015 do que em 2014.
} 
maiores para a base Centro-Sul, e o valor máximo também se encontra nessa região do Brasil. Em relação à CFURH, a média é superior no Centro-Sul, porém o valor máximo se encontra fora dessa região (de fato, o máximo da base se encontra no estado do Pará, devido à usina de Tucuruí). Esse mesmo padrão é visto nas demais variáveis: valores maiores no Centro-Sul do que na base completa. 
Tabela 3: Estatísticas Descritivas - Base Completa (empilhado)

\begin{tabular}{|c|c|c|c|c|c|c|c|}
\hline Estatística/Variável & Média & $1^{\circ}$ Quartil & Mediana & $3^{\circ}$ Quartil & Desv. Pad. & Min & Máx \\
\hline Receita Tributária (reais) & 11.007 .241 & 289.683 & 673.625 & 2.096 .443 & 199.259 .443 & 179 & 17.537.484.677 \\
\hline IPTU (reais) & 2.820 .232 & 9.960 & 48.380 & 269.404 & 57.419 .284 & 0 & 5.027 .438 .496 \\
\hline ISS (reais) & 5.385 .561 & 90.174 & 252.965 & 917.241 & 108.670 .248 & 0 & 9.935 .287 .383 \\
\hline Despesas com Pessoal (reais) & 24.247 .983 & 4.195 .871 & 7.203 .424 & 15.047.529 & 159.542 .517 & 317.062 & 9.406 .770 .282 \\
\hline Despesas com Capital (reais) & 7.450 .180 & 1.002 .854 & 1.937 .998 & 4.160 .927 & 66.892 .845 & 510 & 4.840.327.171 \\
\hline CFURH (reais) & 95.739 & 0 & 0 & 0 & 679.878 & 0 & 30.151 .862 \\
\hline Cota Parte Royalties Petróleo (reais) & 386.646 & 0 & 0 & 0 & 6.094 .635 & 0 & 477.582 .484 \\
\hline Transferências dos Estados (reais) & 38.730 .518 & 8.948 .263 & 14.387.191 & 27.988.291 & 190.075.934 & 0 & 12.699.773.887 \\
\hline Transferências da União (reais) & 17.203 .366 & 5.554 .418 & 7.900 .423 & 14.499 .770 & 54.458 .310 & 0 & 1.975 .521 .340 \\
\hline Cota FPM (reais) & 9.829 .772 & 4.493 .569 & 5.993 .299 & 10.117 .897 & 18.090 .474 & 0 & 711.284 .640 \\
\hline Outras Compensações Financeiras (reais) & 1.088 .425 & 56.092 & 87.203 & 162.537 & 17.708 .201 & 0 & 1.346 .355 .621 \\
\hline População (habitantes) & 34.206 & 5.249 & 11.012 & 23.308 & 202.193 & 804 & 11.376 .685 \\
\hline PIB per capita (reais) & 12.177 & 5.014 & 9.106 & 14.790 & 13.821 & 1.551 & 511.967 \\
\hline PIB (reais) & 624.206 & 41.290 & 87.016 & 224.914 & 6.675 .945 & 4.512 & 499.375 .400 \\
\hline PIB Agrícola (reais) & 30.105 & 7.004 & 15.913 & 33.861 & 48.721 & 0 & 1.143 .504 \\
\hline PIB Agrícola/PIB Total & $21.6 \%$ & $9.1 \%$ & $18,5 \%$ & $32.2 \%$ & $15.6 \%$ & 0 & $82.1 \%$ \\
\hline
\end{tabular}


Tabela 4: Estatísticas Descritivas - Base Centro-Sul (empilhado)

\begin{tabular}{|c|c|c|c|c|c|c|c|}
\hline Variável & Média & $1^{\circ}$ Quartil & Mediana & $3^{\circ}$ Quartil & Desv. Pad. & Min & Máx \\
\hline Receita Tributária (reais) & 15.353 .034 & 343.768 & 873.306 & 3.113 .243 & 253.956 .467 & 12.000 & 17.537.484.677 \\
\hline IPTU (reais) & 4.269 .960 & 33.920 & 118.986 & 586.085 & 73.474 .760 & 0 & 5.027 .438 .496 \\
\hline ISS (reais) & 7.277 .408 & 91.948 & 301.891 & 1.246 .407 & 138.500 .413 & 0 & 9.935 .287 .383 \\
\hline Despesas com Pessoal (reais) & 27.916 .516 & 4.024 .356 & 6.483 .128 & 15.053 .103 & 197.519.249 & 582.200 & 9.406 .770 .282 \\
\hline Despesas com Capital (reais) & 9.268 .444 & 1.108 .736 & 2.096 .035 & 4.637 .452 & 84.668 .943 & 2.358 & 4.840 .327 .171 \\
\hline CFURH (reais) & 116.831 & 0 & 0 & 0 & 562.437 & 0 & 16.655 .462 \\
\hline Cota Parte Royalties Petróleo (reais) & 488.674 & 0 & 0 & 0 & 7.704 .166 & 0 & 477.582 .484 \\
\hline Transferências dos Estados (reais) & 42.763 .876 & 8.727 .953 & 13.106 .837 & 27.870 .735 & 230.783 .505 & 0 & 12.699.773.887 \\
\hline Transferências da União (reais) & 17.013 .989 & 5.339 .286 & 7.134.309 & 13.225 .981 & 57.868 .953 & 0 & 1.975.521.340 \\
\hline Cota FPM (reais) & 9.106 .168 & 4.405 .347 & 5.741 .287 & 9.536 .357 & 11.490 .349 & 0 & 341.416 .627 \\
\hline Outras Compensações Financeiras (reais) & 1.439 .493 & 53.241 & 78.942 & 154.955 & 22.447 .801 & 0 & 1.346 .355 .621 \\
\hline População (habitantes) & 36.108 & 4.478 & 8.990 & 21.055 & 242.334 & 804 & 11.376 .685 \\
\hline PIB per capita (reais) & 15.952 & 8.867 & 12.674 & 18.063 & 15.532 & 2.429 & 511.967 \\
\hline PIB (reais) & 832.514 & 49.121 & 109.048 & 314.441 & 8.438 .935 & 6.708 & 499.375 .400 \\
\hline $\begin{array}{c}\text { PIB Agric. } \\
\text { (reais) }\end{array}$ & 36.574 & 10.471 & 20.883 & 41.935 & 53.559 & 0 & 982.879 \\
\hline \% PIB Agric. & $24.0 \%$ & $10,1 \%$ & $22,8 \%$ & $36,4 \%$ & $16,4 \%$ & 0 & $81,8 \%$ \\
\hline
\end{tabular}




\section{Resultados}

\subsection{Especificação dos Modelos}

Nesta dissertação, a forma adotada para a fronteira estocástica de produção foi a CobbDouglas, dada pela expressão a seguir:

$$
\ln Y_{i}=\beta_{0}+\beta_{1} x_{i 1}+\beta_{2} x_{i 2}+V_{i}-U_{i}
$$

onde:

$Y_{i}$ representa uma medida de esforço fiscal, sendo a Receita Tributária nos modelos 1,2 e 3, e a receita de IPTU nos modelos 4 e 5;

$x_{1}$ representa o logaritmo das despesas com pessoal como proxy para a quantidade de trabalho;

$x_{2}$ representa o logaritmo das despesas com capital como proxy para a quantidade de capital; $V_{i}$ e $U_{i}$ são variáveis aleatórias já definidas na seção 3.3 da presente dissertação.

As variáveis utilizadas foram descritas anteriormente, na seção 3.6.

A equação de ineficiência dada por (6) é dada pelas expressões (12), (13), (14), (15) e (16) para os modelos 1, 2, 3, 4 e 5 respectivamente:

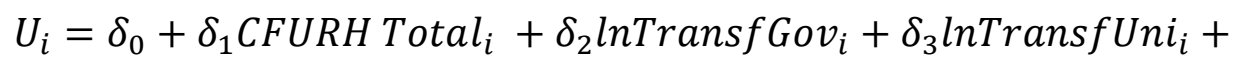

$\delta_{4}$ Outras Comp $_{i}+\delta_{5}$ Lat $_{i}+\delta_{6}$ Long $_{i}+\delta_{7}$ Pop $_{i}+\delta_{8}$ PIBpc $_{i}+\delta_{9} a 2008_{i}+\delta_{10} a 2009_{i}+$ $\delta_{11} a 2010_{i}+\delta_{12} a 2011_{i}+\delta_{13} a 2012_{i}+\delta_{14}$ partidogov $_{i}+\delta_{15}$ partidopres $_{i}$

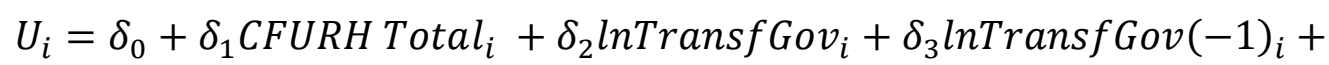

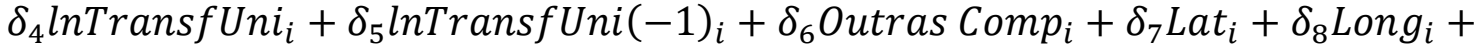
$\delta_{9}$ Pop $_{i}+\delta_{10}$ PIBpc $_{i}+\delta_{11} P \operatorname{IBpc}(-1)_{i}+\delta_{12} a 2008_{i}+\delta_{13} a 2009_{i}+\delta_{14} a 2010_{i}+$ $\delta_{15} a 2011_{i}+\delta_{16} a 2012_{i}+\delta_{17}$ partidogov $_{i}+\delta_{18}$ partidopres $_{i}$ 


$$
U_{i}=\delta_{0}+\delta_{1} \text { CFURH Total } \text { TF }_{i}+\delta_{2} \text { lnTransfGov }_{i}+\delta_{3} \text { InTransfUni }_{i}+
$$

$\delta_{4} \operatorname{Cota~FPM}_{i}+\delta_{5}$ Outras Comp $_{i}+\delta_{6}$ Lat $_{i}+\delta_{7}$ Long $_{i}+\delta_{8}$ Pop $_{i}+\delta_{9}$ PIBpc $_{i}+$ $\delta_{10} a 2008_{i}+\delta_{11} a 2009_{i}+\delta_{12} a 2010_{i}+\delta_{13} a 2011_{i}+\delta_{14} a 2012_{i}$

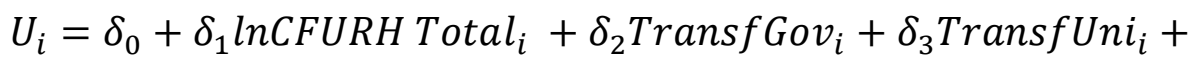

$\delta_{4}$ Outras Comp $_{i}+\delta_{5}$ Lat $_{i}+\delta_{6}$ Long $_{i}+\delta_{7}$ Pop $_{i}+\delta_{8}$ PIBpc $_{i}+\delta_{9}$ PIBagricpct $_{i}+$ $\delta_{10} a 2008_{i}+\delta_{11} a 2009_{i}+\delta_{12} a 2010_{i}+\delta_{13} a 2011_{i}+\delta_{14} a 2012_{i}+\delta_{15}$ partidogov $_{i}+$ $\delta_{16}$ partidopres $_{i}$

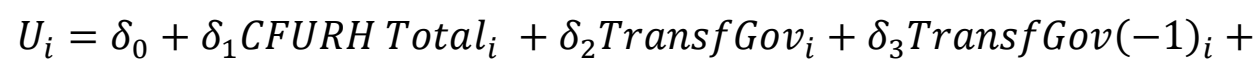
$\delta_{4}$ TransfUni $_{i}+\delta_{5}{\text { TransfUni }(-1)_{i}}+\delta_{6}$ Outras Comp $_{i}+\delta_{7}$ Lat $_{i}+\delta_{8}$ Long $_{i}+\delta_{9}$ Pop $_{i}+$ $\delta_{10}$ PIBpc $_{i}+\delta_{11}$ PIBpc $(-1)_{i}+\delta_{12}$ PIBagricpct $_{i}+\delta_{13} a 2008_{i}+\delta_{14} a 2009_{i}+$ $\delta_{15} a 2010_{i}+\delta_{16} a 2011_{i}+\delta_{17} a 2012_{i}$

em que:

CFURH Total $_{i}$ é o total recebido de CFURH pelo município $i$;

$\operatorname{TransfGov}_{i}$ é o total recebido de transferência do estado pelo município $i$;

TransfUnião $_{i}$ é o total recebido de transferência da União pelo município $i$;

Cota FPM $i$ é o total de recurso recebido através do FPM pelo município $i$;

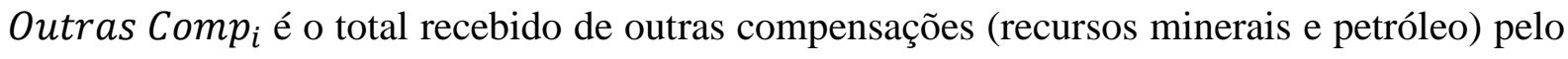
município $i$;

$L_{a} t_{i}$ é a latitude do município $i$;

$\operatorname{Long}_{i}$ é a longitude do município $i$;

$P o p_{i}$ é a população do município $i$;

$P I B p c_{i}$ é o PIB per capita do município $i$;

PIBagricpct $_{i}$ é a razão PIB agrícola/PIB total do município $i$;

$a 2008_{i}$ é uma dummy que assume valor 1 se o ano for 2008, e 0 caso contrário; $a 2009_{i}$ é uma dummy que assume valor 1 se o ano for 2009, e 0 caso contrário; $a 2010_{i}$ é uma dummy que assume valor 1 se o ano for 2010, e 0 caso contrário; $a 2011_{i}$ é uma dummy que assume valor 1 se o ano for 2011, e 0 caso contrário; $a 2012_{i}$ é uma dummy que assume valor 1 se o ano for 2012, e 0 caso contrário; 
$\operatorname{partidogov}_{i}$ é uma dummy que assume valor 1 se o partido do prefeito for o mesmo do governador;

partidopres é uma dummy que assume valor 1 se o partido do prefeito for o mesmo do presidente ou do vice-presidente.

\subsection{Resultados}

Utilizando a base completa e a metodologia de fronteira estocástica, foram obtidos os resultados apresentados nas tabelas 5 e 6 .

Antes de analisarmos os coeficientes de interesse, é necessário checar se o resultado é coerente com o de uma função de produção. Para isso, $\beta_{1}$ e $\beta_{2}$ devem ser positivos e significantes no caso da Cobb-Douglas. Para a função translog, a análise seria mais complicada, pois seria necessário testar a consistência teórica da função em todos os pontos da amostra (Sauer et al, 2006). Além disso, é necessário que $\gamma$ seja positivo e estatisticamente significante. É importante ressaltar que $\gamma$ segue uma distribuição $\chi^{2}$ mista, então seria equivocado interpretar a estatística $t$ usual. Para isso, Kodde Palm (1986) criou um teste LR, com o objetivo de testar se existem ganhos pela utilização da técnica de fronteira estocástica em relação a um simples uso do método dos mínimos quadrados ordinários (MQO). O autor também simulou os valores críticos para alguns graus de liberdade (número de regressores na equação de ineficiência). Tanto o modelo 1 quanto o modelo 2 mostraram-se consistentes com uma função de produção, bem quanto ao ganho do uso da fronteira estocástica em relação ao MQO.

Segundo o modelo 1, o recebimento da CFURH impacta negativamente a arrecadação das receitas tributária, e o coeficiente é estatisticamente significante a 1\%. Além disso, as transferências do governo apresentam um resultado contra intuitivo, impactando positivamente a arrecadação tributária. Uma possível explicação é a de que a transferência do governo é predominantemente de ICMS (Imposto sobre Circulação de Mercadorias e Serviços), que possui caráter devolutivo, ao contrário das demais, que possuem caráter redistributivo. As demais variáveis apresentam sinais consistentes com a literatura: 
transferências da União impactam positivamente a ineficiência arrecadatória, assim como os demais tipos de compensação financeira recebidos pelo município. A latitude e longitude servem como controle para a localização geográfica, já que esta é bastante relacionada à existência de rios e regimes pluviais por exemplo. Por fim, a população impacta positivamente a eficiência do município na arrecadação de imposto, pois a base para tributação é diretamente proporcional ao número de habitantes no local, enquanto o PIB per capita também impacta positivamente a eficiência, pois a arrecadação tributária é maior quando a atividade econômica é maior. Foram utilizadas dummies de ano e de partido, para controlar pela possibilidade de haver maior volume de transferências para municípios em que o partido local é o mesmo do partido do estado ou do país, bem como captar preferências por diferentes quantidades de bem público. Todas as variáveis se mostraram significantes a $1 \%$ de significância.

No modelo 2, foram incluídas as defasagens (identificadas com _1) de algumas variáveis que costumam apresentar certa persistência, com o objetivo de controlar possíveis fatores não observáveis que afetam a eficiência arrecadatória. Espera-se que a variável defasada tenha o mesmo sinal da variável em si, de modo que exista certa persistência. De acordo com o modelo 2 , é possível notar que há robustez a tais fatores, dado que os resultados não se alteram muito em relação ao modelo 1 . O recebimento da CFURH continua a impactar negativamente a eficiência da arrecadação das receitas tributárias e permanece significante ao nível de 1\%. Além disso, as transferências do governo permanecem apresentando um resultado diferente da literatura, impactando positivamente a eficiência arrecadatória. As demais variáveis continuam a apresentar sinais consistentes com a literatura: transferências da União impactam positivamente a ineficiência arrecadatória, assim como os demais tipos de compensação financeira recebidos pelo município. Do outro lado, a população e o PIB per capita impactam negativamente a ineficiência arrecadatória. O controle é feito pela latitude e longitude, e são incluídas dummies de ano e partido político. Em relação às defasagens, todas apresentam de fato o mesmo sinal da variável em si, indicando possível persistência nas transferências do governo, transferências da União e PIB per capita. Todas as variáveis também foram significantes a $1 \%$. 
Tabela 5: Modelo 1 (base completa)

Convergência: 145 iterações

Variável Dependente: $\log (\mathbf{r t})$

\begin{tabular}{|ccc|}
\hline $\begin{array}{c}\text { Função de Produção } \\
(\mathbf{X})\end{array}$ & Coeficiente & Erro-padrão \\
Constante $\left(\boldsymbol{\beta}_{\mathbf{0}}\right)$ & $-2,18^{* * *}$ & $7,06 \mathrm{E}-02$ \\
$\ln D \operatorname{espPes}\left(\boldsymbol{\beta}_{1}\right)$ & $1,05^{* * *}$ & $1,03 \mathrm{E}-02$ \\
$\ln D \operatorname{esp} \operatorname{Cap}\left(\boldsymbol{\beta}_{2}\right)$ & $0,21^{* * *}$ & $5,17 \mathrm{E}-03$ \\
\hline
\end{tabular}

\begin{tabular}{|c|c|c|}
\hline $\begin{array}{l}\text { Eq. Ineficiência } \\
\text { (Z) }\end{array}$ & Coeficiente & Erro-padrão \\
\hline Const $\left(\delta_{0}\right)$ & $1,62^{* * *}$ & $9,87 \mathrm{E}-02$ \\
\hline $\operatorname{CfurhTotal}\left(\delta_{1}\right)$ & $1,39 \mathrm{E}-08^{* * *}$ & $2,59 \mathrm{E}-09$ \\
\hline $\ln$ TransfGov $\left(\delta_{2}\right)$ & $-0,35^{* * *}$ & $1,54 \mathrm{E}-02$ \\
\hline $\operatorname{lnTransfUni}\left(\delta_{3}\right)$ & $0,23^{* * *}$ & $5,10 \mathrm{E}-03$ \\
\hline Outras Comp $\left(\delta_{4}\right)$ & $8,54 \mathrm{E}-10^{* * *}$ & $9,78 \mathrm{E}-11$ \\
\hline Lat $\left(\boldsymbol{\delta}_{5}\right)$ & $1,46 \mathrm{E}-02^{* * *}$ & $2,92 \mathrm{E}-04$ \\
\hline Long $\left(\delta_{6}\right)$ & $1,18 \mathrm{E}-03^{* * *}$ & $2,32 \mathrm{E}-04$ \\
\hline $\operatorname{Pop}\left(\delta_{7}\right)$ & $-1,04 \mathrm{E}-07^{* * *}$ & 3,04E-09 \\
\hline $\operatorname{PIBpc}\left(\delta_{8}\right)$ & $-6,16 \mathrm{E}-03^{* * *}$ & $1,46 \mathrm{E}-04$ \\
\hline Dummies ano & Sim & \\
\hline Dummies partido & Sim & \\
\hline$\gamma$ & 0,46 & $1,23 \mathrm{E}-02$ \\
\hline
\end{tabular}

\footnotetext{
${ }^{* * * *}$ significante a $1 \% ;{ }^{* *}$ significante a $5 \% ;{ }^{*}$ significante a $10 \%$ (t-student) Teste LR: 1,06E+04
}

VC(1\%): 29,93 - Kodde Palm (1986) - 15 g.l. 
Tabela 6: Modelo 2 (base completa)

Convergência: 57 iterações

Variável Dependente: $\log (\mathbf{r t})$

\begin{tabular}{|ccc|}
\hline $\begin{array}{c}\text { Função de Produção } \\
(\mathbf{X})\end{array}$ & Coeficiente & Erro-padrão \\
Constante $\left(\boldsymbol{\beta}_{\mathbf{0}}\right)$ & $-2,63^{* * *}$ & $9,66 \mathrm{E}-02$ \\
$\ln \operatorname{DespPes}\left(\boldsymbol{\beta}_{1}\right)$ & $1,09^{* * *}$ & $1,25 \mathrm{E}-02$ \\
$\ln D \operatorname{esp} \operatorname{Cap}\left(\boldsymbol{\beta}_{2}\right)$ & $0,21^{* * *}$ & $5,65 \mathrm{E}-03$ \\
\hline
\end{tabular}

\begin{tabular}{|c|c|c|}
\hline $\begin{array}{l}\text { Eq. Ineficiência } \\
\text { (Z) }\end{array}$ & Coeficiente & Erro-padrão \\
\hline Const $\left(\delta_{0}\right)$ & $1,07^{* * *}$ & 0,14 \\
\hline $\operatorname{CfurhTotal}\left(\delta_{1}\right)$ & $1,24 \mathrm{E}-08^{* * *}$ & 3,09E-09 \\
\hline $\ln \operatorname{TransfGov}\left(\delta_{2}\right)$ & $-0,18^{* * *}$ & $2,83 \mathrm{E}-02$ \\
\hline $\ln$ TransfGov_1 $\left(\delta_{3}\right)$ & $-0,22^{* * *}$ & $2,10 \mathrm{E}-02$ \\
\hline $\operatorname{lnTransfUni}\left(\delta_{\mathbf{4}}\right)$ & $0,13^{* * *}$ & $2,60 \mathrm{E}-02$ \\
\hline InTransfUni_l $\left(\delta_{5}\right)$ & $0,22^{* * *}$ & $6,81 \mathrm{E}-03$ \\
\hline Outras $\operatorname{Comp}\left(\delta_{6}\right)$ & $7,03 \mathrm{E}-10^{* * *}$ & $1,10 \mathrm{E}-08$ \\
\hline Lat $\left(\delta_{7}\right)$ & $1,58 \mathrm{E}-02^{* * *}$ & $4,25 \mathrm{E}-04$ \\
\hline Long $\left(\delta_{8}\right)$ & $1,04 \mathrm{E}-03^{* * *}$ & $2,83 \mathrm{E}-04$ \\
\hline $\operatorname{Pop}\left(\delta_{9}\right)$ & $-1,09 \mathrm{E}-07^{* * *}$ & $4,46 \mathrm{E}-09$ \\
\hline $\operatorname{PIBpc}\left(\delta_{10}\right)$ & $-4,41 \mathrm{E}-03^{* * *}$ & $2,74 \mathrm{E}-04$ \\
\hline PIBpc_1 $\left(\delta_{11}\right)$ & $-2,05 \mathrm{E}-03^{* * *}$ & $2,86 \mathrm{E}-04$ \\
\hline Dummies ano & Sim & \\
\hline Dummies partido & Sim & \\
\hline$\gamma$ & 0,46 & $1,33 \mathrm{E}-02$ \\
\hline
\end{tabular}

\footnotetext{
${ }^{* * * *}$ significante a $1 \% ;{ }^{* *}$ significante a $5 \% ;{ }^{*}$ significante a $10 \%$ (t-student) Teste LR: 9,04E+03
} VC(1\%): 32,76 - Kodde Palm (1986) - 17g.l. 
Utilizando a base apenas para municípios do Centro-Sul, foram obtidos os resultados expressos nas tabelas 7 a 9 .

Primeiramente, a análise do sinal e da significância dos coeficientes da função de produção nos diz que a fronteira estocástica estima, de fato, uma função de produção, já que todos os betas são positivos e significantes estatisticamente. A análise da estatística LR de Kodde Palm mostra que há ganhos em utilizar esta técnica em relação ao MQO nos três modelos. Posto isso, podemos prosseguir para a análise das equações de ineficiência de cada modelo.

De acordo com o modelo 3, o recebimento da CFURH impacta negativamente a arrecadação das receitas tributárias e seu coeficiente é significante ao nível de $1 \%$ de significância. Além disso, as transferências do governo apresentam um resultado contra intuitivo, impactando positivamente a arrecadação tributária. As demais variáveis apresentam o sinal esperado: transferências da União impactam positivamente a ineficiência arrecadatória, assim como os demais tipos de compensação financeira recebidos pelo município. A cota-parte do Fundo de Participação dos Municípios (FPM) também apresenta um resultado contra intuitivo ao contribuir para elevar a arrecadação tributária. A população e o PIB per capita impactam positivamente a arrecadação, o que é o resultado esperado, pois quanto maior a população e o nível de atividade econômica, maior o recebimento de tributos. Os controles por latitude e longitude para localização geográfica, bem como as dummies de ano foram mantidos, mas não foram utilizadas as dummies de partido. Todos os demais coeficientes também foram estatisticamente significantes ao nível de $1 \%$.

O modelo 4 utiliza a arrecadação do IPTU como variável dependente, pelos motivos discutidos anteriormente (representa melhor o esforço fiscal dos municípios, é mais difícil de sonegar, é mais robusto a ciclos econômicos e devido ao maior grau de urbanização da região Centro-Sul). Segundo o modelo, o recebimento da CFURH impacta negativamente a eficiência de arrecadação das receitas tributárias. O coeficiente é estatisticamente significante ao nível de $1 \%$ Ademais, todas as outras variáveis apresentam o sinal esperado. As transferências, tanto do governo quanto da União, 
impactam positivamente a ineficiência arrecadatória do município, bem como as demais compensações financeiras por ele recebidas. População e PIB per capita municipal impactam negativamente essa ineficiência, ou seja, contribuem para uma maior arrecadação, pelos motivos já citados anteriormente. Nesse modelo, foi incluído a porcentagem do PIB agrícola sobre o PIB total do município, como proxy para o grau de urbanização da localidade, uma vez que o IPTU é um imposto urbano. O sinal dessa variável na equação de ineficiência foi positivo, ou seja, ela contribui para uma maior ineficiência, o que é intuitivo pois, quanto maior o PIB agrícola, menor a arrecadação do IPTU. O controle foi feito pela latitude, longitude, dummies de ano e de partido político. Todas as demais variáveis mostraram-se significantes ao nível de $1 \%$.

Por fim, o modelo 5 inclui variáveis defasadas como forma de captar uma possível persistência da ineficiência no modelo. No entanto, algumas variáveis como transferências da União ao município e PIB per capita deixaram de ser estatisticamente significantes a $10 \%$. Além disso, a variável população passou a apresentar um sinal contra intuitivo. O recebimento da CFURH permaneceu impactando negativamente a eficiência na arrecadação municipal, sendo estatisticamente significante ao nível de $1 \%$ de significância, o que mostra robustez do resultado obtido nos modelos anteriores. 
Tabela 7: Modelo 3 (base Centro-Sul)

Convergência: 293 iterações

Variável Dependente: $\log (\mathbf{r t})$

\begin{tabular}{|ccc|}
\hline $\begin{array}{c}\text { Função de Produção } \\
(\mathbf{X})\end{array}$ & Coeficiente & Erro-padrão \\
Constante $\left(\boldsymbol{\beta}_{\mathbf{0}}\right)$ & $-2,10^{* * *}$ & $5,11 \mathrm{E}-02$ \\
$\ln \operatorname{DespPes}\left(\boldsymbol{\beta}_{1}\right)$ & $1,07^{* * *}$ & $8,89 \mathrm{E}-03$ \\
$\ln \operatorname{Desp} \operatorname{Cap}\left(\boldsymbol{\beta}_{2}\right)$ & $0,17^{* * *}$ & $6,53 \mathrm{E}-03$ \\
\hline
\end{tabular}

\begin{tabular}{|c|c|c|}
\hline $\begin{array}{c}\text { Eq. Ineficiência } \\
\text { (Z) }\end{array}$ & Coeficiente & Erro-padrão \\
\hline Const $\left(\delta_{0}\right)$ & $2,82 \mathrm{E}+02^{* * *}$ & $7,43 \mathrm{E}-02$ \\
\hline $\operatorname{CfurhTotal}\left(\delta_{1}\right)$ & $2,98 \mathrm{E}-08^{* * *}$ & $3,52 \mathrm{E}-09$ \\
\hline $\ln T r a n s f G o v\left(\delta_{2}\right)$ & $-0,51^{* * *}$ & $1,17 \mathrm{E}-02$ \\
\hline $\ln T r a n s f U n i\left(\delta_{3}\right)$ & $0,21^{* * *}$ & $9,28 \mathrm{E}-03$ \\
\hline $\ln \operatorname{CotaFPM}\left(\delta_{4}\right)$ & $-1,85 \mathrm{E}-02^{* * *}$ & $7,18 \mathrm{E}-03$ \\
\hline Outras Comp $\left(\delta_{5}\right)$ & $1,08 \mathrm{E}-09^{* * *}$ & $8,23 \mathrm{E}-11$ \\
\hline Lat $\left(\delta_{6}\right)$ & $1,17 \mathrm{E}-03^{* * *}$ & $4,92 \mathrm{E}-04$ \\
\hline Long $\left(\delta_{7}\right)$ & $3,44 \mathrm{E}-03^{* * *}$ & $3,31 \mathrm{E}-04$ \\
\hline $\operatorname{Pop}\left(\delta_{8}\right)$ & $-3,71 \mathrm{E}-08^{* * *}$ & 3,19E-09 \\
\hline $\operatorname{PIBpc}\left(\delta_{9}\right)$ & $-3,93 \mathrm{E}-03^{* * *}$ & $1,15 \mathrm{E}-04$ \\
\hline Dummies ano & Sim & \\
\hline Dummies partido & Não & \\
\hline$\gamma$ & 0,39 & $1,65 \mathrm{E}-02$ \\
\hline
\end{tabular}

*** significante a $1 \% ;{ }^{* *}$ significante a $5 \% ;{ }^{*}$ significante a $10 \%$ (t-student)

Teste LR: 2,18E+03

VC(1\%): 31,35 - Kodde Palm (1986) - 16 g.l. 
Tabela 8: Modelo 4 (base Centro-Sul)

Convergência: 60 iterações

Variável Dependente: $\log (i p t u)$

\begin{tabular}{|ccc|}
\hline $\begin{array}{c}\text { Função de Produção } \\
(\mathbf{X})\end{array}$ & Coeficiente & Erro-padrão \\
Constante $\left(\boldsymbol{\beta}_{\mathbf{0}}\right)$ & $-5,81^{* * *}$ & $4,84 \mathrm{E}-02$ \\
$\ln D \operatorname{espPes}\left(\boldsymbol{\beta}_{1}\right)$ & $1,45^{* * *}$ & $1,22 \mathrm{E}-02$ \\
$\ln D \operatorname{esp} \operatorname{Cap}\left(\boldsymbol{\beta}_{2}\right)$ & $0,21^{* * *}$ & $1,09 \mathrm{E}-02$ \\
\hline
\end{tabular}

\begin{tabular}{|c|c|c|}
\hline $\begin{array}{c}\text { Eq. Ineficiência } \\
\text { (Z) }\end{array}$ & Coeficiente & Erro-padrão \\
\hline Const $\left(\delta_{0}\right)$ & $-3,24^{* * *}$ & 0,15 \\
\hline $\ln C$ furhTotal $\left(\delta_{1}\right)$ & $1,95 \mathrm{E}-07^{* * *}$ & $2,25 \mathrm{E}-08$ \\
\hline $\operatorname{TransfGov}\left(\delta_{2}\right)$ & $2,92 \mathrm{E}-09^{* * *}$ & $9,50 \mathrm{E}-10$ \\
\hline $\operatorname{TransfUni}\left(\delta_{3}\right)$ & $1,64 \mathrm{E}-09^{* * *}$ & $8,39 \mathrm{E}-10$ \\
\hline Outras Comp $\left(\delta_{\mathbf{4}}\right)$ & $4,37 \mathrm{E}-09^{* * *}$ & $9,37 \mathrm{E}-10$ \\
\hline Lat $\left(\delta_{5}\right)$ & $0,46^{* * *}$ & $1,21 \mathrm{E}-02$ \\
\hline Long $\left(\delta_{6}\right)$ & $-7,81 \mathrm{E}-02^{* * *}$ & $3,71 \mathrm{E}-03$ \\
\hline $\operatorname{Pop}\left(\delta_{7}\right)$ & $-2,59 \mathrm{E}-06^{* * *}$ & $9,63 \mathrm{E}-07$ \\
\hline $\operatorname{PIBpc}\left(\delta_{8}\right)$ & $-1,59 \mathrm{E}-02^{* * *}$ & $4,45 \mathrm{E}-04$ \\
\hline PIBagricpct $\left(\delta_{9}\right)$ & $3,44^{* * *}$ & 0,12 \\
\hline Dummies ano & Sim & \\
\hline Dummies partido & Sim & \\
\hline$\gamma$ & 0,97 & 8,88E-04 \\
\hline
\end{tabular}

*** significante a $1 \% ;{ }^{* *}$ significante a $5 \% ;{ }^{*}$ significante a $10 \%$ (t-student)

Teste LR: 7,94E+03

VC(1\%): 31,35 - Kodde Palm (1986) - 16 g.1. 
Tabela 9: Modelo 5 (base Centro-Sul)

Convergência: 37 iterações

Variável Dependente: $\log (i p t u)$

\begin{tabular}{|ccc|}
\hline $\begin{array}{c}\text { Função de Produção } \\
(\mathbf{X})\end{array}$ & Coeficiente & Erro-padrão \\
Constante $\left(\boldsymbol{\beta}_{\mathbf{0}}\right)$ & $-5,29^{* * *}$ & $8,12 \mathrm{E}-02$ \\
$\ln D \operatorname{espPes}\left(\boldsymbol{\beta}_{1}\right)$ & $1,38^{* * *}$ & $1,02 \mathrm{E}-02$ \\
$\ln D \operatorname{esp} \operatorname{Cap}\left(\boldsymbol{\beta}_{2}\right)$ & $0,21^{* * *}$ & $1,43 \mathrm{E}-02$ \\
\hline
\end{tabular}

\begin{tabular}{|c|c|c|}
\hline $\begin{array}{c}\text { Eq. Ineficiência } \\
\text { (Z) }\end{array}$ & Coeficiente & Erro-padrão \\
\hline Const $\left(\delta_{0}\right)$ & $2,17^{* * *}$ & 0,75 \\
\hline $\operatorname{CfurhTotal}\left(\delta_{2}\right)$ & $6,70 \mathrm{E}-08^{* * *}$ & $1,97 \mathrm{E}-08$ \\
\hline $\operatorname{TransfGov}\left(\delta_{2}\right)$ & $-0,38^{* *}$ & 0,18 \\
\hline TransfGov_l$\left(\delta_{3}\right)$ & $-0,88^{* * *}$ & 0,14 \\
\hline $\operatorname{TransfUni}\left(\delta_{4}\right)$ & 0,26 & 0,36 \\
\hline TransfUni_1( $\left.\delta_{5}\right)$ & $0,81^{* * *}$ & $7,09 \mathrm{E}-03$ \\
\hline Outras Comp $\left(\delta_{6}\right)$ & $2,98 \mathrm{E}-09^{* * *}$ & $5,29 \mathrm{E}-10$ \\
\hline Lat $\left(\delta_{7}\right)$ & $0,11^{* * *}$ & $3,45 \mathrm{E}-03$ \\
\hline Long $\left(\delta_{\mathbf{8}}\right)$ & $-1,68 \mathrm{E}-02^{* * *}$ & $1,43 \mathrm{E}-03$ \\
\hline $\operatorname{Pop}\left(\delta_{9}\right)$ & $2,86 \mathrm{E}-07^{* * *}$ & $6,41 \mathrm{E}-08$ \\
\hline $\operatorname{PIBpc}\left(\delta_{10}\right)$ & $-3,65 \mathrm{E}-03$ & $2,76 \mathrm{E}-03$ \\
\hline PIBpc $\_1\left(\delta_{11}\right)$ & $6,97 \mathrm{E}-03^{* *}$ & $3,33 \mathrm{E}-03$ \\
\hline PIBagricpct $\left(\delta_{12}\right)$ & $1,13^{* * *}$ & 0,13 \\
\hline Dummies ano & Sim & \\
\hline Dummies partido & Não & \\
\hline$\gamma$ & 0,92 & $2,11 \mathrm{E}-03$ \\
\hline
\end{tabular}

\footnotetext{
${ }^{* * * *}$ significante a $1 \% ;{ }^{* *}$ significante a $5 \% ;{ }^{*}$ significante a $10 \%$ (t-student)

Teste LR: 6,32E+03
}

VC(1\%): 31,35 - Kodde Palm (1986) - 16g.l. 
Com os resultados obtidos, podemos concluir que o fato do município receber a CFURH afeta negativamente seu esforço fiscal, mas este impacto mostrou-se pequeno. O resultado é robusto a diferentes especificações, inclusive com a mudança na variável dependente de receita tributária total para receitas de IPTU na base restrita ao CentroSul.

Outra vantagem de utilizar a técnica de fronteiras estocásticas é que ela fornece rankings de eficiência dos municípios. Dessa forma, podemos analisar se os principais beneficiários da CFURH são, em geral, menos eficientes no sentido arrecadatório do que a média dos demais municípios. Essa comparação é feita nas tabelas 10 e 11, utilizando a média dos dados entre 2007 e 2012. Os valores em destaque representam aqueles que estão abaixo da média de eficiência de todos os municípios.

Tabela 10: Eficiência Técnica para CFURH Total - Base Completa

\begin{tabular}{ccccc}
\hline Município & UF & CFURH (R\$) & Ef. Técnica Média 1 & Ef. Técnica Média 2 \\
\hline Novo Repartimento & PA & $25.194 .525,64$ & $\mathbf{3 9 , 5 7 \%}$ & $\mathbf{5 0 , 2 2 \%}$ \\
Paulo Afonso & BA & $18.417 .569,13$ & $\mathbf{5 7 , 9 9 \%}$ & $\mathbf{6 2 , 8 0 \%}$ \\
Niquelândia & GO & $10.145 .526,44$ & $72,76 \%$ & $74,85 \%$ \\
Goianésia do Pará & PA & $9.367 .987,05$ & $\mathbf{4 7 , 2 7 \%}$ & $\mathbf{4 9 , 8 7 \%}$ \\
Tucuruí & GO & $9.087 .798,83$ & $\mathbf{6 5 , 5 1 \%}$ & $\mathbf{5 5 , 2 3 \%}$ \\
Canindé de São & SE & $7.454 .612,98$ & $\mathbf{6 0 , 5 5 \%}$ & $\mathbf{6 5 , 7 8 \%}$ \\
Fransico & & $6.448 .052,00$ & $\mathbf{5 5 , 1 7 \%}$ & $\mathbf{5 2 , 6 7 \%}$ \\
DelmiroGouveia & AL & $6.236 .481,82$ & $\mathbf{5 0 , 2 9 \%}$ & $\mathbf{5 7 , 4 3 \%}$ \\
SentoSé & BA & $74,55 \%$ & $\mathbf{5 6 , 4 7 \%}$ \\
Sacramento & MG & $6.135 .723,37$ & $71,24 \%$ & $\mathbf{6 8 , 1 3 \%}$ \\
Santa Vitória & MG & $5.630 .696,41$ & Elaboraç̃̃o do autor
\end{tabular}

Eficiência Técnica Média - Modelo 1: 65,80\%

Eficiência Técnica Média - Modelo 2: 69,61\% 
Tabela 11: Eficiência Técnica para CFURH Total - Base Centro-Sul

\begin{tabular}{|c|c|c|c|c|c|}
\hline Município & $\mathbf{U F}$ & CFURH (R\$) & $\begin{array}{c}\text { Ef. Técnica } \\
\text { Média } 3\end{array}$ & $\begin{array}{c}\text { Ef. Técnica } \\
\text { Média } 4\end{array}$ & $\begin{array}{c}\text { Ef. Técnica } \\
\text { Média } 5\end{array}$ \\
\hline Niquelândia & $\mathrm{GO}$ & $10.145 .526,44$ & $75,82 \%$ & $47,88 \%$ & $41,36 \%$ \\
\hline Sacramento & MG & $6.135 .723,37$ & $77,46 \%$ & $73,35 \%$ & $69,01 \%$ \\
\hline Santa Vitória & MG & $5.630 .696,41$ & $75,86 \%$ & $43,86 \%$ & $40,38 \%$ \\
\hline Corumbaíba & GO & $5.079 .131,86$ & $68,25 \%$ & $73,51 \%$ & $67,72 \%$ \\
\hline $\begin{array}{c}\text { Morada Nova de } \\
\text { Minas }\end{array}$ & MG & $5.026 .129,46$ & $61,46 \%$ & $64,67 \%$ & $57,30 \%$ \\
\hline Bituruna & PR & $4.918 .762,23$ & $68,43 \%$ & $75,79 \%$ & $68,93 \%$ \\
\hline Cruz Machado & PR & 4.914.541,19 & $66,59 \%$ & $59,91 \%$ & $52,25 \%$ \\
\hline $\begin{array}{c}\text { Aparecida do } \\
\text { Taboado }\end{array}$ & MS & $4.830 .358,25$ & $79,95 \%$ & $76,35 \%$ & $72,02 \%$ \\
\hline Chopinzinho & PR & $4.385 .931,70$ & $76,74 \%$ & $82,38 \%$ & $80,57 \%$ \\
\hline Pinhão & PR & $4.289 .628,32$ & $74,01 \%$ & $70,67 \%$ & $64,76 \%$ \\
\hline
\end{tabular}

Eficiência Técnica Média - Modelo 3: 74,96\%

Eficiência Técnica Média - Modelo 4: 69,80\%

Eficiência Técnica Média - Modelo 5: 64,80\%

É possível notar que, na tabela 10, todos os municípios que pertencem ao Norte ou Nordeste brasileiros estão abaixo da média de eficiência técnica de arrecadação de tributos. É importante ressaltar que a maior parte desses municípios das regiões citadas recebe a compensação devido à usina hidrelétrica de Tucuruí. Outro ponto interessante é a mudança no índice de eficiência no município de Niquelândia (GO). Nos modelos 4 e 5 da tabela 11, quando a variável dependente passa a ser o IPTU, a eficiência tributária despenca, mesmo considerando que a razão entre PIB agrícola e PIB total seja de $6,86 \%$. Tal fato ocorre devido a grande exploração de níquel, responsável pela maior parte do produto interno bruto do município. 
Utilizando o valor da CFURH per capita, esses rankings mudam, conforme as tabelas 12 e 13 abaixo. Note que todos os estados pertencem ao Centro-Sul do país.

Tabela 12: Eficiência Técnica para CFURH per capita - Base Completa

\begin{tabular}{ccccc}
\hline Município & UF & $\begin{array}{c}\text { CFURH per } \\
\text { capita(R\$) }\end{array}$ & Ef. Técnica Média 1 & Ef. Técnica Média 2 \\
\hline Grupiara & MG & $1.967,19$ & $\mathbf{5 1 , 9 1 \%}$ & $\mathbf{6 1 , 9 7 \%}$ \\
Três Ranchos & GO & 977,72 & $67,86 \%$ & $\mathbf{6 7 , 1 7 \%}$ \\
Cascalho Rico & MG & 975,92 & $\mathbf{6 1 , 8 5 \%}$ & $84,74 \%$ \\
Douradoquara & MG & 899,51 & $\mathbf{5 3 , 9 9 \%}$ & $\mathbf{7 0 , 2 0 \%}$ \\
Campinaçu & GO & 845,51 & $\mathbf{5 4 , 6 2 \%}$ & $\mathbf{6 7 , 6 6 \%}$ \\
Celso Ramos & SC & 750,06 & $\mathbf{6 4 , 4 3 \%}$ & $86,63 \%$ \\
Rubinéia & SP & 646,49 & $70,40 \%$ & $88,23 \%$ \\
Pinhal da Serra & PR & 641,38 & $67,31 \%$ & $\mathbf{7 4 , 8 7 \%}$ \\
Mariano Moro & RS & 629,29 & $\mathbf{6 4 , 2 9 \%}$ & $87,79 \%$ \\
Corumbaíba & GO & 619,19 & $67,92 \%$ & $\mathbf{6 4 , 6 7 \%}$ \\
\hline
\end{tabular}

Eficiência Técnica Média - Modelo 1: 65,80\%

Eficiência Técnica Média - Modelo 2: 69,61\%

Tabela 13: Eficiência Técnica para CFURH per capita - Base Centro-Sul

\begin{tabular}{cccccc}
\hline Município & UF & $\begin{array}{c}\text { CFURH per } \\
\text { capita(R\$) }\end{array}$ & $\begin{array}{c}\text { Ef. Técnica } \\
\text { Média 3 }\end{array}$ & $\begin{array}{c}\text { Ef. Técnica } \\
\text { Média 4 }\end{array}$ & $\begin{array}{c}\text { Ef. Técnica } \\
\text { Média 5 }\end{array}$ \\
\hline Grupiara & MG & $1.967,19$ & $\mathbf{5 3 , 7 1 \%}$ & $\mathbf{3 4 , 3 6 \%}$ & $\mathbf{2 7 , 4 4 \%}$ \\
Três Ranchos & GO & 977,72 & $\mathbf{6 7 , 5 3 \%}$ & $74,21 \%$ & $\mathbf{4 8 , 4 0 \%}$ \\
Cascalho Rico & MG & 975,92 & $\mathbf{6 2 , 6 5 \%}$ & $\mathbf{3 4 , 4 6 \%}$ & $\mathbf{2 9 , 9 5 \%}$ \\
Douradoquara & MG & 899,51 & $\mathbf{5 5 , 6 4 \%}$ & $\mathbf{3 1 , 3 1 \%}$ & $\mathbf{2 7 , 6 1 \%}$ \\
Campinaçu & GO & 845,51 & $\mathbf{5 8 , 0 8 \%}$ & $\mathbf{4 8 , 0 1 \%}$ & $\mathbf{3 9 , 8 9 \%}$ \\
Celso Ramos & SC & 750,06 & $\mathbf{6 2 , 1 4 \%}$ & $\mathbf{5 0 , 5 8 \%}$ & $\mathbf{4 0 , 8 4 \%}$ \\
Rubinéia & SP & 646,49 & $\mathbf{7 1 , 2 2 \%}$ & $86,70 \%$ & $85,45 \%$ \\
Pinhal da Serra & PR & 641,38 & $\mathbf{7 1 , 5 6 \%}$ & $\mathbf{4 3 , 6 5 \%}$ & $\mathbf{3 1 , 3 1 \%}$ \\
Mariano Moro & RS & 629,29 & $\mathbf{6 2 , 1 1 \%}$ & $81,40 \%$ & $76,29 \%$ \\
Corumbaíba & GO & 619,19 & $\mathbf{6 8 , 2 5 \%}$ & $73,51 \%$ & $67,72 \%$ \\
\hline
\end{tabular}

Eficiência Técnica Média - Modelo 3: 74,96\%

Eficiência Técnica Média - Modelo 4: 69,80\%

Eficiência Técnica Média - Modelo 5: 64,80\% 
De acordo com o modelo 3, todos os municípios estão abaixo da média de eficiência arrecadatória, o que corrobora com a hipótese inicial de que o recebimento da CFURH pode causar um relaxamento fiscal por parte dos municípios que a recebem.

\section{Considerações Finais}

Assim como os recursos não renováveis, os recursos hídricos não estão isentos de impactos ambientais. Estes impactos são remediados através da Compensação Financeira pela Utilização dos Recursos Hídricos (CFURH). No entanto, o recebimento desses recursos suscita outro problema na literatura fiscal: o fato de que transferências verticais criam um cenário para um possível relaxamento fiscal por parte dos municípios. Com o aumento da pressão de ambientalistas para a redução do impacto da construção de uma hidrelétrica, a maior parte das usinas mais recentes não possui reservatório. São as chamadas usinas fio d'água, cuja produção de energia fica muito suscetível ao volume de água do rio. Como a CFURH é uma porcentagem do valor total da energia produzida pelas usinas, um longo período de estiagem pode reduzir consideravelmente o recurso recebido pelos municípios que, se deixarem de arrecadar, podem ficar sem recursos para importantes áreas como a educação, segurança e saúde. Por tal motivo, torna-se importante verificar se o recebimento da CFURH causa um relaxamento fiscal por parte das localidades, o que foi feito através da metodologia de fronteira estocástica. Foram rodados modelos para municípios do Brasil todo e para aqueles pertencentes somente à região Centro-Sul.

Os resultados indicam que, na média, o impacto da CFURH sobre a arrecadação municipal existe, mas é pequeno. No entanto, devido à forte assimetria da distribuição desses recursos, as localidades que mais dependem desses recursos podem ter problemas orçamentários se o volume recebido cair abruptamente. Além disso, a técnica permitiu a estimação de rankings de eficiência técnica da arrecadação. Em geral, os municípios que mais recebem CFURH e CFURH per capita são menos eficientes na arrecadação do que a média de todos os municípios. 
Uma possível política para evitar o relaxamento fiscal seria a intensificar a fiscalização existente, que se dá pelo Tribunal de Contas ou Ministério Público dos estados, para evitar problemas identificados por Caselli e Michaels (2009) relacionados à corrupção e outras atividades ilícitas por parte dos prefeitos dos municípios beneficiários dos royalties do petróleo e por Monteiro e Ferraz (2010) que é hipertrofia do quadro de funcionários públicos.

A metodologia de fronteira estocástica possui suas limitações. Embora ela possa ser aplicada a diversas áreas, ela se baseia na estimação de uma fronteira de produção hipotética e, portanto, não é possível fazer grandes modificações, além da forma funcional como a Cobb-Douglas e a Translog, discutidas nesta dissertação. Apenas a equação de ineficiência permite maior flexibilidade, mas não há muito espaço para discussão da identificação, por exemplo. Além disso, há muito mais para explorar na área de recursos hídricos e o impacto da CFURH na eficiência da arrecadação municipal. É possível aplicar outras técnicas, como propensity score, bem como utilizar variáveis de georreferenciamento. No entanto, os resultados obtidos são muito importantes para a questão hídrica, cuja importância tem crescido ao longo do tempo, bem como para traçar um paralelo com a literatura de transferências verticais e esforço fiscal. 


\section{Referências}

AFRIAT, Sidney N. Efficiency estimation of production functions. International Economic Review, p. 568-598, 1972.

AIGNER, Dennis J.; CHU, Shih-fan. On estimating the industry production function. The American Economic Review, v. 58, n. 4, p. 826-839, 1968.

AIGNER, Dennis; LOVELL, C. A.; SCHMIDT, Peter. Formulation and estimation of stochastic frontier production function models. Journal of Econometrics, v. 6, n. 1, p. 21-37, 1977.

ARAGON, F., \& GAYOSO, V. (2005).Intergovernmental transfers and fiscal effort in Peruvian local governments. Working paper, Munich Personal RePEc Archive.

BATTESE, George E. et al. Estimation of a production frontier model: with application to the pastoral zone of Eastern Australia. Australian journal of agricultural economics, v. 21, n. 3, p. 169-179, 1977.

BATTESE, George E.; COELLI, Tim J. Frontier production functions, technical efficiency and panel data: with application to paddy farmers in India. Springer Netherlands, 1992.

BATTESE, George Edward; COELLI, Tim J. A model for technical inefficiency effects in a stochastic frontier production function for panel data. Empirical economics, v. 20, n. 2, p. 325-332, 1995.

BUETTNER, Thiess. The incentive effect of fiscal equalization transfers on tax policy. Journal of Public Economics, v. 90, n. 3, p. 477-497, 2006. 
CARNICELLI, Lauro; POSTALI, Fernando Antonio Slaibe. Rendas do petróleo e tributos locais: uma análise de propensity score. Anais do XL Encontro Nacional de Economia-Anpec, 2012.

CASELLI, Francesco; MICHAELS, Guy. Do oil windfalls improve living standards? Evidence from Brazil. National Bureau of Economic Research, 2009.

CHARNES, Abraham; COOPER, William W.; RHODES, Edwardo. Measuring the efficiency of decision making units. European journal of operational research, v. 2, n. 6, p. 429-444, 1978.

COSSIO, F. (1998). Disparidades Interregionais, Capacidade de Obtenção de Recursos Tributários. Esforço Fiscal e Gasto Público no Federalismo Brasileiro. Rio de Janeiro: BNDES.

DAHLBERG, Matz et al. Using a discontinuous grant rule to identify the effect of grants on local taxes and spending. Journal of Public Economics, v. 92, n. 12, p. 23202335, 2008.

DAHLBY, Bev. The marginal cost of public funds and the flypaper effect. International Tax and Public Finance, v. 18, n. 3, p. 304-321, 2011.

FEARNSIDE, Philip M. Social impacts of Brazil's Tucurui dam. Environmental Management, v. 24, n. 4, p. 483-495, 1999.

FRIEDMAN, Renato. Compensações financeiras pela exploração de recursos naturais da União: política atual e recomendações de reforma. 2003. Estudo ${ }^{\circ}$. 29, Consultoria Legislativa do Senado Federal.

GREENE, William H. A gamma-distributed stochastic frontier model. Journal of econometrics, v. 46, n. 1, p. 141-163, 1990. 
HARTWICK, J. M. Intergenerational equity and the investing of rents from exhaustible resources. American Economic Review, 67, nº 5, p. 972-974, 1977

HENSENGERTH, Oliver; DOMBROWSKI, I.; SCHEUMANN, Waltina. Benefitsharing on dams on shared rivers. 2012.

IGLIORI, Danilo Camargo. Determinants of technical efficiency in agriculture and cattle ranching: A spatial analysis for the Brazilian Amazon. University of Cambridge Land Economy Working Paper, n. 09.2005, 2005.

IMORI, Denise. Eficiência produtiva da agropecuária familiar e patronal nas regiões brasileiras. 2011. Tese de Doutorado. Universidade de São Paulo.

JONDROW, James; Lovell, C. A. K; Materov, Ivan S; Schmidt, Peter. On the estimation of technical inefficiency in the stochastic frontier production function model. Journal of econometrics, v. 19, n. 2, p. 233-238, 1982.

KUMBHAKAR, Subal C.; LOVELL, CA Knox. Stochastic frontier analysis. Cambridge University Press, 2003.

LEAL, Jose Agostinho; SERRA, Rodrigo. Uma investigação sobre os critérios de repartição dos royalties petrolíferos. In: PIQUET, Rosélia (org.). Petróleo, royalties e região. Rio de Janeiro: Garamond, 2003, p. 163-164.

MEEUSEN, Wim; VAN DEN BROECK, J. Technical efficiency and dimension of the firm: Some results on the use of frontier production functions. Empirical economics, v. 2, n. 2, p. 109-122, 1977.

MONTEIRO, Joana; FERRAZ, Claudio. Does oil make leaders unaccountable? Evidence from Brazil's offshore oil boom. unpublished, PUC-Rio, 2010.

OATES, W. (1999).An essay on fiscal federalism. Journal of Economic Literature, 37(3), 1120-1149. 
POSTALI, Fernando Antonio Slaibe. Petroleum royalties and regional development in Brazil: The economic growth of recipient towns. Resources Policy, v. 34, n. 4, p. 205$213,2009$.

POSTALI, Fernando Antonio Slaibe. Tax effort and oil royalties in the Brazilian municipalities. EconomiA, v. 16, n. 3, p. 395-405, 2015.

POSTALI, F., \& NISHIJIMA, M. (2008). O retorno social dos royalties do petróleo nos municípios brasileiros. Anais do XXXVI Encontro Nacional de Economia ANPEC, Salvador, 2008.

SLAIBE POSTALI, F. A.; NISHIJIMA, M. Distribuição das rendas do petróleo e indicadores de desenvolvimento municipal no Brasil nos anos 2000. Estudos Econômicos, v. 41, n. 2, p. 463-485, 2011.

POSTALI, Fernando Antonio Slaibe; NISHIJIMA, Marislei. Oil windfalls in Brazil and their long-run social impacts. Resources Policy, v. 38, n. 1, p. 94-101, 2013.

POSTALI, F., \& ROCHA, F. (2009). Resource windfalls, fiscal effort and public spending: Evidence from Brazilian municipalities. Anais do XXXVII Encontro Nacional de Economia ANPEC, Foz do Iguaçu, 2009.

QUEIROZ C., \& POSTALI, F. (2010). Rendas do Petróleo e Eficiência Tributária nos Municípios Brasileiros. XXXVIII Encontro Nacional de Economia - Anpec. Salvador.

RIBEIRO, E. P., \& SHIKIDA, C. D. (2000). Existe Trade-off entre Receitas Próprias e Transferências? O Caso dos Municípios Mineiros. CEDEPLAR.

RICHMOND, James. Estimating the efficiency of production. International economic review, p. 515-521, 1974. 
SANGUINETTI, Pablo; TOMMASI, Mariano. Intergovernmental transfers and fiscal behavior insurance versus aggregate discipline. Journal of International Economics, v. 62, n. 1, p. 149-170, 2004.

SAUER, Johannes; FROHBERG, Klaus; HOCKMANN, Heinrich. Stochastic efficiency measurement: the curse of theoretical consistency. Journal of Applied Economics, v. 9, n. 1, p. 139-165, 2006.

SERRA, Rodrigo Valente. Desdobramento Espacial da Exploração e Produção de Petróleo no Brasil: em busca de um nexo para a distribuição dos royalties entre os Municípios. Anais: Encontros Nacionais da ANPUR, v. 10, 2013.

STEVENSON, Rodney E. Likelihood functions for generalized stochastic frontier estimation. Journal of econometrics, v. 13, n.1, p. 57-66, 1980.

VARIAN, Hal R. Intermediate microeconomics: a modern approach. New York, NY: WW Norton \& Company, 2010.

WILDI, Walter. Environmental hazards of dams and reservoirs. Near Curriculum in Natural Environmental Science, v. 88, p. 187-197, 2010. 